\title{
Numerical experiments of storm winds, surges, and waves on the southern coast of Korea during Typhoon Sanba: the role of revising wind force
}

\author{
J. J. Yoon, J. S. Shim, K. S. Park, and J. C. Lee \\ Department of coastal disaster prevention center, Korea Institute of Ocean Science \& Technology (KIOST), 787 Haean-ro, \\ Sangnok-gu, Ansan, South Korea
}

Correspondence to: J. J. Yoon (jjyoon@kiost.ac)

Received: 28 May 2014 - Published in Nat. Hazards Earth Syst. Sci. Discuss.: 20 August 2014

Revised: 4 November 2014 - Accepted: 4 November 2014 - Published: 8 December 2014

\begin{abstract}
The southern coastal area of Korea has often been damaged by storm surges and waves due to the repeated approach of strong typhoons every year. The integrated model system is applied to simulate typhoon-induced winds, storm surges, and surface waves in this region during Typhoon Sanba in 2012. The TC96 planetary boundary layer wind model is used for atmospheric forcing and is modified to incorporate the effect of the land's roughness on the typhoon wind. Numerical experiments are carried out to investigate the effects of land-dissipated wind on storm surges and waves using the three-dimensional, unstructured grid, Finite Volume Coastal Ocean Model (FVCOM), which includes integrated storm surge and wave models with highly refined grid resolutions along the coastal region of complex geometry and topography. Compared to the measured data, the numerical models have successfully simulated storm winds, surges, and waves. Better agreement between the simulated and measured storm winds has been found when considering the effect of wind dissipation by land roughness. In addition, this modified wind force leads to clearly improved results in storm surge simulations, whereas the wave results have shown only slight improvement. The study results indicate that the effect of land dissipation on wind force plays a significant role in the improvement of water level modeling inside coastal areas.
\end{abstract}

\section{Introduction}

Increases in storm intensity and incidence along with rising sea levels due to climate change have resulted in a higher probability of damage caused by inundation from storm surges in major coastal areas located in low-lying coastal regions around the world. Every year, the Korean Peninsula is attacked by a number of typhoons, some of which cause significant damage to coastal cities. In particular, if a typhoon makes landfall on a southern coastal area, storm surges and high waves are more likely to occur, which could lead to significant damage. The southern coast of the Korean Peninsula consists of complicated coastal lines, with a large number of islands of a variety of sizes. For this reason, in the case of the major coastal areas that reside in the inner bay, storm surges that occur during high tide tend to produce more damage than those from waves.

In 2003, Typhoon Maemi struck the southern coast of Korea. The typhoon killed 131 people and destroyed about USD 4.2 billion worth of property. Ever since, there has remained a high possibility of typhoon damage every year in coastal areas (Kawai et al., 2005; Lee et al., 2008; Kwon et al., 2008; Kang, 2009; Yoon and Shim, 2013). Therefore, measures to protect property and lives against these natural disasters require urgent establishment. However, the sole use of hardware structures such as shore protections and coastal dykes cannot completely prevent the damage of inundation caused by storm surges and high waves. Besides these preventive structures, it is necessary to deploy numerical prediction systems that enable authorities to respond natural disasters promptly, in order to cope with the damage that might arise from typhoons in a systematic manner. In developing numerical prediction systems, it is important to analyze regional distribution characteristics precisely with previous storm surge heights. It is also necessary to investigate long-term observation data accurately in order to predict the areas that storm surges might affect with precision. Fine-grid 
numerical ocean models that consider oceanic forces such as tides, surges, and wave patterns should be comprehensively established in conjunction with accurate atmospheric models.

In this study, integrated numerical simulation was performed for storm surges and surface waves in the southern coastal areas of Korea using an unstructured-grid finite volume model - FVCOM (Chen et al., 2004, 2006). In addition, a planetary boundary layer (PBL) model TC96 (Cardone et al., 1994; Thompson and Cardone, 1996) was applied to evaluate surface meteorological forces. In accurately simulating surges and waves that are induced by typhoons, an exact input of the sea-surface wind and air pressure as atmospheric forces are of critical importance. In this sense, in order to perform sea-surface wind estimations more accurately, the simulation of typhoon wind field is refined by incorporating the land dissipation effect on wind passing through the land. Additionally, this study compares the differences between two cases, depending on whether the refined wind forcing results are used, to find out how much the refined simulation results contribute to the improvement of the ocean model's results for storm surges and surface waves. Previous studies related to the simulation of storm surges by revising wind forces were mainly conducted in southern Louisiana (Westerink et al., 2008; Bunya et al., 2010; Dietrich et al., 2011a; Sheng et al., 2010). However, there have been no research studies that have considered this effect in Korea.

As for the roughness length $\left(z_{0}\right)$ information of the land, a land cover map data was used, which was provided by the Korean Ministry of Environment (KME) through the website, egis.me.go.kr. Based on this land cover map, the roughness lengths for each grid corresponding to the entire area of the Korean Peninsula and adjacent ocean are calculated. The estimated values are used when taking into account the effect of wind dissipation due to the land roughness effect.

In order to simulate typhoon-induced surges and waves efficiently, we have employed unstructured triangular grids to cover the northwestern Pacific Ocean and East China Sea. In addition, integrated simulation is performed on the tides, storm surges, and waves for Typhoon Sanba, which occurred in 2012. Then, the simulation results were compared to the observed data. Through this, we investigated the influence of the wind dissipation effect on the simulations of storm winds, surges, and waves.

Brief information about Typhoon Sanba and the observation system is described in Sect. 2. Section 3 notes the introduction of the storm wind model and discusses the results of wind/pressure estimation as meteorological forces. Section 4 includes the description of an ocean circulation model for storm surges and waves, and the following results and discussion of simulations are added in Sect. 4. Finally, our conclusions are summarized in Sect. 5.

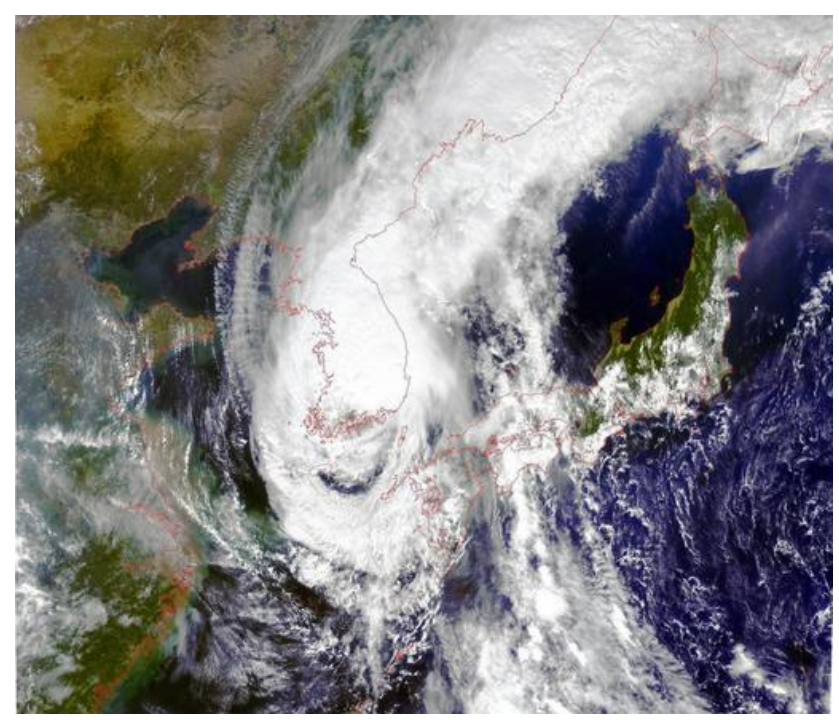

Figure 1. Satellite Chollian GOCI RGB Synthetic image for Typhoon Sanba.

\section{Typhoon Sanba and observation system}

Typhoon Sanba (TY1216), which was the 16th typhoon originating in the northwestern Pacific Ocean in 2012, was the most powerful typhoon of 2012. At first, it was produced as a small-scale typhoon in a distant ocean, $1530 \mathrm{~km}$ away from Manila, the Philippines on 11 September 2012. As it moved north, into the vicinity of Okinawa, Japan, it grew bigger. As time went by, the typhoon became more powerful because the path through which it originated and traveled coincided with the season with the highest sea surface temperature. Before approaching the Korean Peninsula, it moved north with an average speed of $26 \mathrm{~km} \mathrm{~h}^{-1}$. Once it came close to the southern coast of the Korean Peninsula, it turned northeast with a higher speed of $43 \mathrm{~km} \mathrm{~h}^{-1}$. It then landed on the Korean Peninsula and traveled through it. The typhoon affected some coastal areas, including Yeosu, Masan, and Geoje (see Fig. 4), with accompanying strong winds of over $20 \mathrm{~m} \mathrm{~s}^{-1}$ of maximum instantaneous wind speed, heavy rain of $60 \mathrm{~mm} \mathrm{~h}^{-1}$, and over $100 \mathrm{~cm}$ added surge height, which became much worse in conjunction with the high tide from midnight to 01:00 (UTC), 17 September. These areas were inundated and were severely damaged by it. Figure 1 is an image taken by a satellite immediately before Typhoon Sanba landed on the Korean Peninsula. The image indicates that the typhoon well maintained its influential radius and circular shape at a large size until it made landfall on the coast. Figure 2 shows the tracking path taken by Typhoon Sanba and the distribution of its central pressures.

Figure 3 depicts two curves: the central maximum wind speed and the barometric pressure that were recorded; both are plotted against time. The data was obtained by referring to the best track data provided by the Joint Typhoon Warn- 


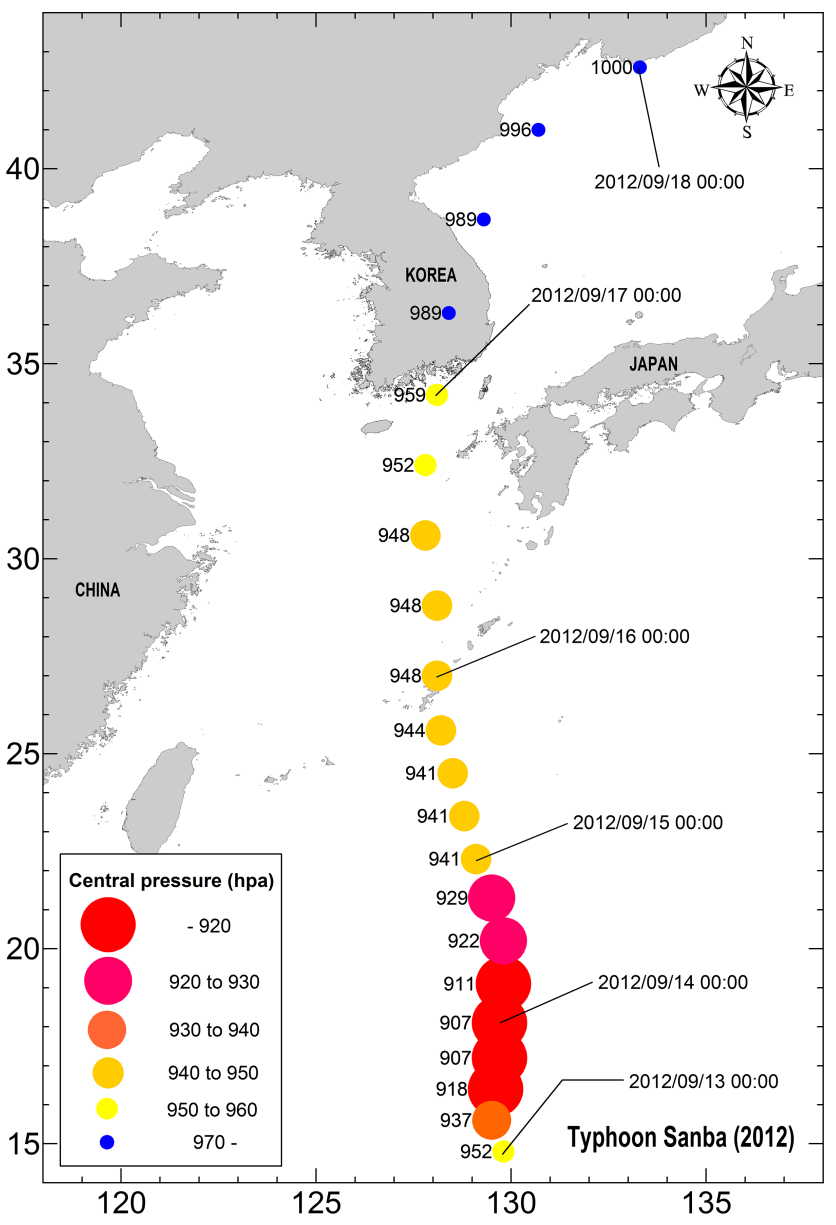

Figure 2. Track of Typhoon Sanba.

ing Center (JTWC) run by the US Navy. The data indicates that the maximum wind speed reached $80 \mathrm{~m} \mathrm{~s}^{-1}$, and strong winds were maintained at about $44 \mathrm{~m} \mathrm{~s}^{-1}$, even up until it landed on the Korean Peninsula. However, it is indicated that the wind power was greatly reduced after landfall.

The present study made use of a wide variety of data obtained from ocean and meteorological observation caused by Typhoon Sanba. There are various tidal stations and ocean observation buoys installed around the coastal sea of Korea, and they are run on a realtime basis. The major ocean observation institutes are as follows: Korea Hydrographic and Oceanographic Administration (KHOA), Korea Meteorological Administration (KMA), Korea Institute of Ocean Science \& Technology (KIOST) and National Fisheries Research \& Development Institute (NFRDI), etc. Figure 4 is a map that shows the locations of the observation stations that are located close to the tracking path of the typhoon. In this study, the data produced by those stations were used. The stations in the figure are distinguished by each institute running them. Table 1 lists the information on the respective observation station and types of observed data. There are 15 meteorological stations, 8 water-level stations, and 9 wave stations

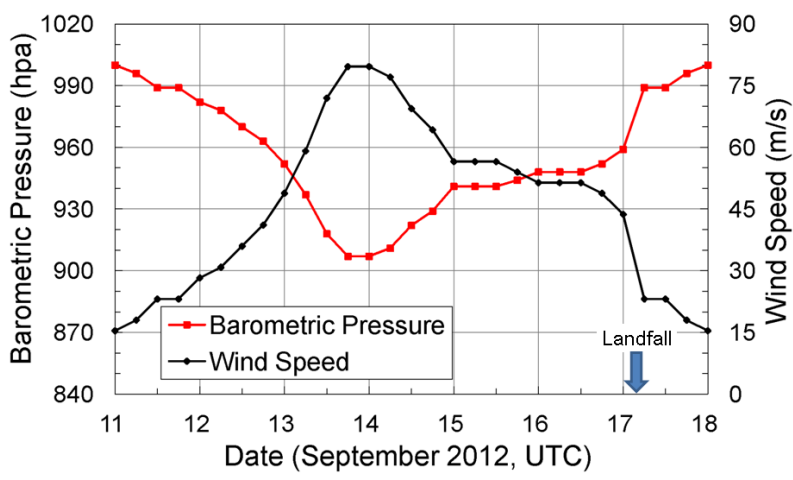

Figure 3. The central maximum wind speed and air pressure during Typhoon Sanba.

near the coasts. These observed data are used to verify the simulation results for winds, storm surges, and wave parameters.

\section{Simulation of surface wind forcing}

\subsection{Typhoon wind model}

In an ocean circulation model, a typhoon directly induces changes in wind stress on the sea surface, which leads to a rising sea level. Therefore, in an ocean model that estimates storm surges and wave profiles, an exact simulation of the wind field is the most important stage. Lots of research studies have been conducted for evaluating the effect that typhoons have on sea-surface winds as follows: (1) analytical parametric model by Holland (1980) and Xie et al. (2006), (2) steady-state dynamic planetary boundary layer model of TC96, (3) non-steady dynamic models of MM5 (S. S. Chen et al., 2007), WRF (Skamarock et al., 2005; Corbosiero et al., 2007), GFDL (Bender et al., 2007), and WINDGEN (Graber et al., 2006), and (4) kinematic models of $\mathrm{H}^{*}$ wind (Powell et al., 1998, 2010) and IOKA (Cox et al., 1995).

Among these models, the sea-surface wind model using typhoon parameters has the advantage of more accurately reproducing the wind field centered on the typhoon. This model enables prompt calculation, so that it can be useful for storm surge prediction systems. To perform an exact evaluation of the sea-surface wind, it is therefore critical to acquire an accurate set of data regarding the typhoon, such as the center location of the typhoon's track, the radius of the maximum wind speed, the central pressure, and the moving speed. The model suggested by Holland (1980) is a simple analytic model that assumes that the typhoon parameter is a concentric circle. Xie et al. (2006) suggests a distribution equation incorporating an asymmetric vortex in which the maximum wind speed varies at different degrees of azimuth.

In this study, the TC96 model, which is the PBL model, is applied to evaluate the sea-surface wind of the typhoon. The 
Table 1. Information from the observation stations.

\begin{tabular}{|c|c|c|c|c|c|c|c|}
\hline \multirow{2}{*}{$\begin{array}{l}\text { Data } \\
\text { source }\end{array}$} & \multirow{2}{*}{$\begin{array}{l}\text { Station } \\
\text { name }\end{array}$} & \multirow{2}{*}{$\begin{array}{l}\text { Station } \\
\text { type }\end{array}$} & \multirow{2}{*}{$\begin{array}{l}\text { Location } \\
\text { (Lat / Long) }\end{array}$} & \multicolumn{4}{|c|}{ Data type } \\
\hline & & & & Wind & Atm. Pressure & Water level & Wave \\
\hline \multirow{12}{*}{ KHOA } & Goheung & tide station & $34^{\circ} 28^{\prime} 51^{\prime \prime} \mathrm{N}, 127^{\circ} 20^{\prime} 33^{\prime \prime} \mathrm{E}$ & - & - & - & $\mathrm{X}$ \\
\hline & Gwangyang & tide station & $34^{\circ} 54^{\prime} 02^{\prime \prime} \mathrm{N}, 127^{\circ} 45^{\prime} 27^{\prime \prime} \mathrm{E}$ & - & - & - & $\mathrm{X}$ \\
\hline & Yeosu & tide station & $34^{\circ} 44^{\prime} 50^{\prime \prime} \mathrm{N}, 127^{\circ} 45^{\prime} 57^{\prime \prime} \mathrm{E}$ & - & - & - & $X$ \\
\hline & Tongyeong & tide station & $34^{\circ} 49^{\prime} 40^{\prime \prime} \mathrm{N}, 128^{\circ} 26^{\prime} 05^{\prime \prime} \mathrm{E}$ & - & - & - & $X$ \\
\hline & Geoje & tide station & $34^{\circ} 48^{\prime} 06^{\prime \prime} \mathrm{N}, 128^{\circ} 41^{\prime} 57^{\prime \prime} \mathrm{E}$ & - & - & - & $\mathrm{X}$ \\
\hline & Masan & tide station & $35^{\circ} 12^{\prime} 36^{\prime \prime} \mathrm{N}, 128^{\circ} 35^{\prime} 20^{\prime \prime} \mathrm{E}$ & - & - & - & $\mathrm{X}$ \\
\hline & Gadeok & tide station & $35^{\circ} 01^{\prime} 18^{\prime \prime} \mathrm{N}, 128^{\circ} 48^{\prime} 47^{\prime \prime} \mathrm{E}$ & - & - & - & $\mathrm{X}$ \\
\hline & Busan & tide station & $35^{\circ} 05^{\prime} 46^{\prime \prime} \mathrm{N}, 129^{\circ} 02^{\prime} 07^{\prime \prime} \mathrm{E}$ & - & - & - & $X$ \\
\hline & Busan new port & ultrasonic wave meter & $35^{\circ} 04^{\prime} 28^{\prime \prime} \mathrm{N}, 128^{\circ} 47^{\prime} 13^{\prime \prime} \mathrm{E}$ & - & - & $X$ & - \\
\hline & Haeundae & buoy & $35^{\circ} 08^{\prime} 55^{\prime \prime} \mathrm{N}, 129^{\circ} 10^{\prime} 07^{\prime \prime} \mathrm{E}$ & - & - & $\mathrm{X}$ & - \\
\hline & K-GA-S02 & buoy & $34^{\circ} 55^{\prime} 59^{\prime \prime} \mathrm{N}, 129^{\circ} 08^{\prime} 16^{\prime \prime} \mathrm{E}$ & - & - & $\mathrm{X}$ & - \\
\hline & K-GA-S03 & buoy & $34^{\circ} 13^{\prime} 26^{\prime \prime} \mathrm{N}, 128^{\circ} 25^{\prime} 03^{\prime \prime} \mathrm{E}$ & - & - & $\mathrm{X}$ & - \\
\hline \multirow{4}{*}{ KMA } & Geoje buoy & buoy & $34^{\circ} 46^{\prime} 00^{\prime \prime} \mathrm{N}, 128^{\circ} 54^{\prime} 02^{\prime} \mathrm{E}$ & - & - & $\mathrm{X}$ & - \\
\hline & Ganyeoam & lighted buoy & $34^{\circ} 17^{\prime} 06^{\prime \prime} \mathrm{N}, 127^{\circ} 51^{\prime} 28^{\prime \prime} \mathrm{E}$ & - & - & $\mathrm{X}$ & - \\
\hline & Gwangan & lighted buoy & $35^{\circ} 07^{\prime} 54^{\prime \prime} \mathrm{N}, 129^{\circ} 08^{\prime} 09^{\prime \prime} \mathrm{E}$ & - & - & $\mathrm{X}$ & - \\
\hline & Dumido & wave buoy & $34^{\circ} 44^{\prime} 40^{\prime \prime} \mathrm{N}, 128^{\circ} 10^{\prime} 30^{\prime \prime} \mathrm{E}$ & $X$ & $\mathrm{X}$ & $X$ & - \\
\hline KI-ST & Yeosu buoy & buoy & $34^{\circ} 23^{\prime} 08^{\prime \prime} \mathrm{N}, 127^{\circ} 51^{\prime} 09^{\prime \prime} \mathrm{E}$ & $X$ & $\mathrm{X}$ & $\mathrm{X}$ & - \\
\hline
\end{tabular}

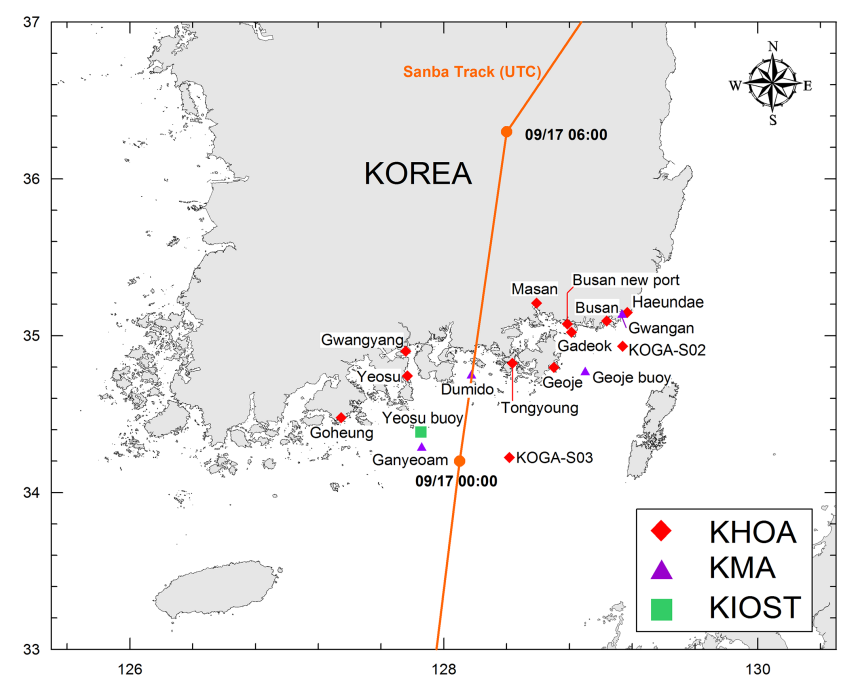

Figure 4. The location of observation stations on the southern coast of Korea.

TC96 model is capable of numerical analysis for primitive equations of motion including the physical processes occurring at the PBL. The TC96 model is based on the horizontal motion equations, vertically averaged through the PBL. This model was first developed into a practical tool by the Ocean Data Gathering Program (ODGP). Then the model was improved by Cardone et al. (1994) and Thompson and Cardone (1996) with the support of the US Army Corps of Engineers. The major parameters are the location of the typhoon's center, its minimum central pressure, the radius of maximum wind, and maximum wind speed. The pressure field is composed of the sum of the axially symmetric parts in terms of the exponential pressure profile from Holland (1980) and the large-scale pressure field of constant gradient. In this sense, an accurate simulation can be achieved by evaluating the values of the parameters mentioned above. These analysis and forecast data of the northern Pacific are provided by the Korea Meteorological Administration (KMA), the Regional Specialized Meteorological Center (RSMC) run by Japan Meteorological Administration (JMA), and the Joint Typhoon Warning Center (JTWC) run by the US Navy.

Among the major parameters related to a typhoon, the radius of the maximum wind is one of the critical factors in determining the spatial profile. The radius of the maximum wind denotes a distance from the center of a typhoon to a position at which the maximum wind speed is produced. The radius of the maximum wind can be estimated in several ways, as follows: direct measurement by aircraft, the satellite method (Hsu et al., 2000; Hsu and Babin, 2005), and the use of empirical equations (Anthes, 1982; Kieu, 2012). However, there are many constraints to consider when evaluating the radius of maximum wind quantitatively. RSMC and KMA do not provide the radius of the maximum wind values, while JTWC provides the values contained in their best track data since 2001. Hence, in this study, we use the latest version of best track data regarding Typhoon Sanba released by JTWC. 


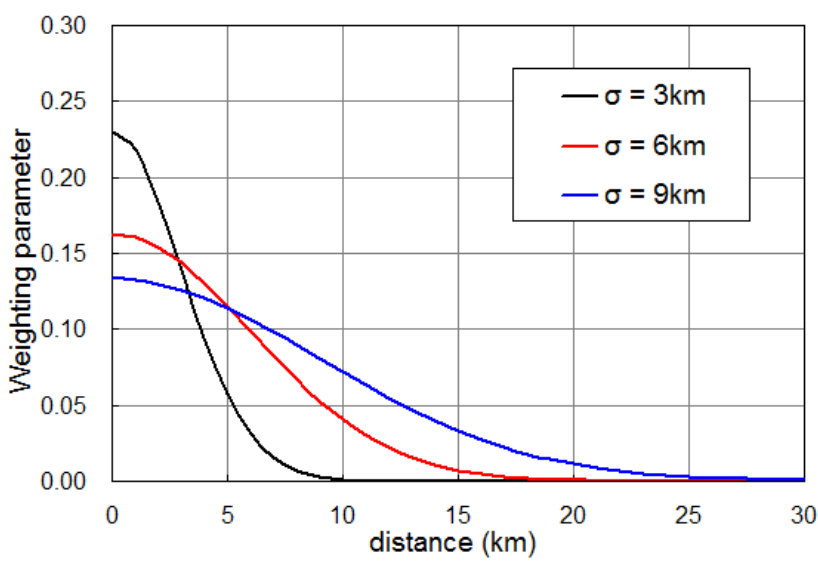

Figure 5. Exponential weighting parameter for the variability of $\sigma$.

\subsection{Effect of land dissipation on typhoon winds}

Wind blowing over land areas suffers a reduction in speed due to the surface roughness effect, depending on the land usage conditions, which directly influence sea-surface winds. Therefore, when estimating the sea-surface wind, which is considered the main surface force for the ocean model, the effect of land surface heterogeneity on the wind passing through the land should be taken into account. In order to reflect the land usage features of coastal areas realistically in an atmospheric model, an accurate and specific land cover map for the land surface should be applied. In the case of a regional atmospheric model such as WRF, several physical features such as albedo, moisture availability, roughness length, and thermal inertia are applied to the model, so that it can simulate the changes of atmospheric thermal structure more accurately (Lam et al., 2006).

In this study, for considering the effect of land surface roughness in evaluating sea-surface wind at a coastal region, wind reduction factor was estimated using a function of roughness lengths $\left(z_{0}\right)$. Generally, numerical models use land cover data sets from the US Geological Survey (USGS). This data set is derived from the satellite sensor data with a $1 \mathrm{~km}$ resolution from the Advanced Very High Resolution Radiometer (NOAA/AVHRR). The data is developed for the purpose of global environmental research and applied models (Loveland et al., 2000). However, the data set created by the USGS is 15 years old and has low resolution. This means that the data does not include changes of land-use cover due to city expansion and the large-scale reclamation projects that have been carried out since the 2000s in Korea. In order to overcome this gap, this study uses the land cover map data provided by the Environmental Geographic Information System (egis.me.go.kr) run by the Korean Ministry of Environment (KME). The KME's land cover map classifies the regions into 22 classes, in accordance with regional characteristics as shown in Table 2. The data classified is denoted in various polygons based on the Geographic Information Sys-

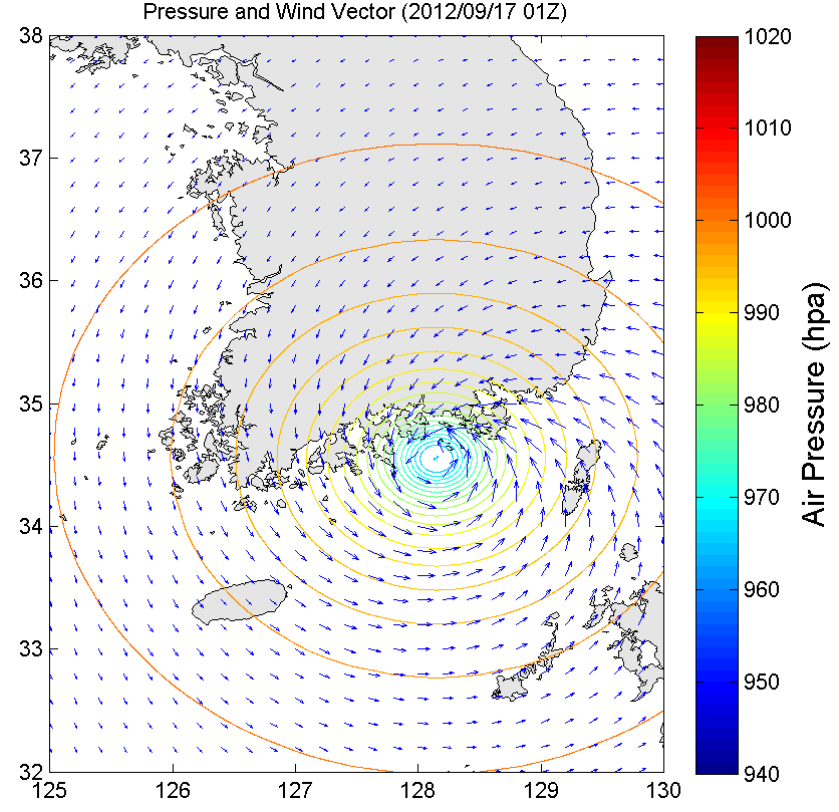

Figure 6. An example of a simulated typhoon wind field before landfall.

tem (GIS), and is being updated periodically. The most recent (2009) version of the data is used in this study. In order to apply the polygon-type data to the numerical model, it has been converted to raster-format data with a $30 \mathrm{~m}$ interval spatial distribution. In terms of information on surface roughness lengths $\left(z_{0}\right)$ for each land use type, we referred to the National Land Cover Dataset (NLCD) LA-GAP conducted by the U.S. Geological Survey (USGS) in Louisiana (Hartley et al., 2000). Then it is rearranged in accordance with classes provided by KME's land cover map. The rearranged data are presented in Table 2.

Directional land masking procedures are applied to consider the land effect on a wind field produced by a typhoon wind model. Wind dissipation due to the land roughness effect is characterized by land use cover features such as urban, forested, agricultural, and wetland for each region, which is similar to classifying the surface roughness length $\left(z_{0}\right)$ as shown in Table 2. Directional roughness values $\left(z_{0_{\text {land-dir }-k}}\right)$ for each of the 12 upwind directions are estimated at each computational grid of the TC96 model by adding the weighted average of roughness length depending on a distance within $10 \mathrm{~km}$ upwind of the computational grid as in Eq. (1).

$z_{0_{\mathrm{land}-\mathrm{dir}-k}}=\frac{\sum_{i=0}^{n} w(i) z_{0_{\mathrm{land}}}(i)}{\sum_{i=0}^{n} w(i)}$,

where $n$ denotes the total number of land cover pixel points within $10 \mathrm{~km}$ for each of $k=1,12$ upwind directions. The 
Table 2. A comparison of the nominal surface roughness lengths $\left(z_{0}\right)$ between the KME and NLCD data sources.

\begin{tabular}{|c|c|c|c|c|c|}
\hline \multicolumn{3}{|c|}{ KME } & \multicolumn{3}{|c|}{ NLCD } \\
\hline Class & Land cover category & $z_{0}(\mathrm{~m})$ & Class & Land cover category & $z_{0}(\mathrm{~m})$ \\
\hline 110 & Residential & 0.55 & 11 & Open water & 0.001 \\
\hline 120 & Industrial & 0.55 & 12 & Ice/snow & 0.012 \\
\hline 130 & Commercial & 0.39 & 21 & Low residential & 0.33 \\
\hline 140 & Cultural \& recreational & 0.05 & 22 & High residential & 0.5 \\
\hline 150 & Traffic area & 0.33 & 23 & Commercial & 0.39 \\
\hline 160 & Public facilities & 0.33 & 31 & Bare rock/sand & 0.09 \\
\hline 210 & Row crops & 0.06 & 32 & Gravel pit & 0.18 \\
\hline 220 & Small grains & 0.05 & 33 & Transitional & 0.18 \\
\hline 230 & Greenhouse & 0.06 & 41 & Deciduous forest & 0.65 \\
\hline 240 & Orchard & 0.06 & 42 & Evergreen forest & 0.72 \\
\hline 250 & Pasture & 0.06 & 43 & Mixed forest & 0.71 \\
\hline 310 & Deciduous forest & 0.65 & 51 & Shrub land & 0.12 \\
\hline 320 & Evergreen forest & 0.72 & 61 & Orchard/vineyard & 0.27 \\
\hline 330 & Mixed forest & 0.71 & 71 & Grassland & 0.04 \\
\hline 410 & Natural grassland & 0.04 & 81 & Pasture & 0.06 \\
\hline 420 & Artificial grassland & 0.04 & 82 & Row crops & 0.06 \\
\hline 510 & Inland wetland & 0.55 & 83 & Small grains & 0.05 \\
\hline 520 & Coastal wetland & 0.11 & 84 & Fallow & 0.04 \\
\hline 610 & Bare rock/sand & 0.09 & 85 & Recreational grass & 0.05 \\
\hline 620 & Barren & 0.04 & 91 & Woody wetland & 0.55 \\
\hline 710 & Open water & 0.001 & 92 & Herbaceous wetland & 0.11 \\
\hline 720 & Sea & 0.001 & - & - & - \\
\hline
\end{tabular}

weighting parameter is defined as Eq. (2),

$w(i)=\frac{1}{\sqrt{2 \pi \sigma}} e^{\frac{-d(i)^{2}}{2 \sigma^{2}}}$,

where $d$ is a distance between the computational grid node and each position of the land cover data and $\sigma$ is the distance indicating the importance of the closest data. In this study, $\sigma$ is set to $3 \mathrm{~km}$. As seen in Fig. 5, a distance for exponential weighting factor varies at different values of $\sigma$. When $\sigma$ equals $3 \mathrm{~km}$, the $10 \mathrm{~km}$ of weighting distance can be applied, while the $20 \mathrm{~km}$ of weighting distance can be applied when $\sigma$ is $6 \mathrm{~km}$, and $30 \mathrm{~km}$ of weighting distance can be applied at a $\sigma$ of $9 \mathrm{~km}$.

First, the database is completed by calculating the values of $z_{0 \text { land-dir }}$ for each of the 12 upwind directions at each grid using Eq. (1). Subsequently, based on the values of $z_{0_{\text {land-dir }}}$ for each upwind direction at distinct times for each grid point, the wind reduction coefficient is calculated using Eq. (3), which was proposed by Powell et al. (1996).

$f_{\text {dir }-k}=\left(\frac{z_{0_{\text {marine }}}}{z_{0_{\text {land-dir }-k}}}\right)^{0.0706}$,

where $z_{0_{\text {marine }}}$ denotes open water roughness and $z_{0_{\text {land-dir }}}$ denotes the weighted upwind land roughness at the corresponding grid point. Finally, $W_{10}$, which is the wind speed considering the wind dissipation effect in the TC96 model, is eval- uated by applying reduction coefficient $f$ as below.

$W_{10}=f_{\text {dir-k }} \cdot W_{10_{\text {org }}}$

In particular, if the area where wind originates includes an inland region, the upwind effect incurs wind speed reductions. Conversely, if the wind blows from sea towards the land, it is not necessary to consider the land roughness effect. In the cases of nearshore zone and low-lying regions that are more likely to get damaged by the sea-level rising or flooding due to storm surges, it is critically important to evaluate accurate sea-surface wind fields, including this effect. This is because the shallow water equations used for calculating the total water height respond most sensitively to surface wind stresses. This method was first proposed by Powell et al. $(1996,1998)$ and then applied to the ADCIRC (Luettich et al., 1992; Westerink et al., 1994) model. Ever since, this method has been applied consistently to many studies on hurricanes, incorporating numerical models such as in Westerink et al. (2008), Bunya et al. (2010), Sheng et al. (2010) and Dietrich et al. (2011a, b).

\subsection{Storm wind results}

The wind and atmospheric pressure fields at the time when Typhoon Sanba lands were evaluated using a TC96 model. For evaluating typhoon wind fields, the effect that occurs by applying land cover features in coastal areas is analyzed. A spatial distribution of $30 \mathrm{~min}$ averaged wind and pressure 
Table 3. A comparison of index $d$ and RMSE on the influence of the land roughness effect for each station (see Figs. 4 and 9 , and Table 1 for locations).

\begin{tabular}{|c|c|c|c|c|c|}
\hline \multirow[b]{2}{*}{$\begin{array}{l}\text { Station } \\
\text { name }\end{array}$} & \multicolumn{2}{|c|}{$\begin{array}{c}\text { Index } d \\
\text { (Wind speed) }\end{array}$} & \multicolumn{2}{|c|}{$\begin{array}{c}\text { RMSE } \\
\text { (Wind speed, } \mathrm{ms}^{-1} \text { ) }\end{array}$} & \multirow[b]{2}{*}{$\begin{array}{r}\text { RMSE } \\
\text { (Air pressure, hpa) }\end{array}$} \\
\hline & $\begin{array}{r}\text { Land } \\
\text { dissipation } \\
\text { OFF }\end{array}$ & $\begin{array}{r}\text { Land } \\
\text { dissipation } \\
\mathrm{ON}\end{array}$ & $\begin{array}{r}\text { Land } \\
\text { dissipation } \\
\mathrm{OFF}\end{array}$ & $\begin{array}{r}\text { Land } \\
\text { dissipation } \\
\mathrm{ON}\end{array}$ & \\
\hline Goheung & 0.929 & 0.988 & 5.43 & 1.96 & 4.12 \\
\hline Yeosu & 0.678 & 0.885 & 5.69 & 3.47 & 3.19 \\
\hline Tongyoung & 0.963 & 0.992 & 8.70 & 3.74 & 3.05 \\
\hline Geoje & 0.923 & 0.981 & 6.14 & 2.63 & 4.00 \\
\hline Masan & 0.972 & 0.993 & 10.39 & 5.05 & 2.73 \\
\hline Gadeok & 0.934 & 0.959 & 7.19 & 5.14 & 3.34 \\
\hline Busan & 0.975 & 0.992 & 10.55 & 5.72 & 1.95 \\
\hline Busan new port & 0.964 & 0.989 & 8.65 & 4.49 & 2.60 \\
\hline Mean & 0.917 & 0.972 & 7.84 & 4.03 & 3.12 \\
\hline
\end{tabular}

fields is produced from the TC96 model. The wind results are supposed to be generated in an unstructured grid of preoperational ocean model FVCOM, which will be described in Sect. 4. The reason the estimated wind data would be projected onto the unstructured grid of the ocean model is to make the grid structures of the atmospheric and ocean models identical, which consequently enables the removal of errors that might happen due to the difference between the two grid structures.

Figures 6 provides snapshot, illustrating wind fields with air pressure distribution by simulation of a typhoon at a time immediately before the typhoon arrives on land. The concentric-type pressure field stands out clearly in Fig. 6. In addition, Fig. 7 depicts the simulation results for the wind fields in several distinct cases, including whether the wind dissipation effect by the different land use types is taken into account. As for the wind passing through inland, the simulation results indicate that wind dissipation was more likely to be simulated well in coastal areas when considering the land roughness effects compared to otherwise. When offshore, wind dissipation effects rarely occur. However, since the southern coast is composed of mountainous areas, complicated coastlines, and many islands, wind dissipation effects are evident because of the influence of the land. These effects are more likely to stand out in the western region of typhoon center. The simulation results indicate that the amount of wind reduction (directed offshore) that occurs was up to about $13 \mathrm{~m} \mathrm{~s}^{-1}$ in the case of Typhoon Sanba (Fig. 7c). However, in the ocean area where the eastern part of typhoon's eye suffered no effects from the land, there was no reduction in wind speed (directed onshore). The simulation results show that the maximum wind speed during the typhoon reached up to about $35 \mathrm{~m} \mathrm{~s}^{-1}$ near Tongyoung. The object of this study is to enhance the accuracy of sea-surface wind evaluation through these methods and to refine and improve the simulation of storm surges and surface waves.

Wind and pressure field results evaluated by the typhoon wind model were compared to observation data. For better comparison, meteorological observation data around these areas centering on landfall position of typhoon were collected as much as possible. Locations where observation was carried out and types of observation data are as shown in Fig. 4 and Table 1. The observation data were reanalyzed to 30 min averaged values. These values were converted into the values $10 \mathrm{~m}$ above the surface level considering the height of each observation device using the power law method (Hsu et al., 1994).

Figure 8 compares wind speed and air pressure by depicting both simulation results based on the TC96 model and measured data for each observation station during Typhoon Sanba. The model results are divided again, by whether or not the land dissipation effect is considered. All locations where observations were conducted are tide stations located in coastal areas, where the highest surge height most likely occurs. According to the figures, it is indicated that in the cases where land dissipation effect is not considered, the wind speed is generally overestimated compared to observation data. This can be one of the main causes of spatial errors in simulating storm surges and surface waves. The analysis of this symptom will be discussed in Sects. 4.3 and 4.4. In terms of air pressure, a numerical simulation is carried out with no regard to land usage type. Even though there is a constraint in that the pressure distribution is assumed as a concentric shape, the simulation results indicate that the pressure distribution is reproduced quite well, as shown in Fig. 8. Additionally, we used the indices of $d$ proposed by Willmott (1981) and the Root Mean Square Error (RMSE) to establish a quantitative measure of the time-series results 
Table 4. The simulated and observed maximum storm surge heights for each scenario (see Figs. 4 and 9, and Table 1 for locations).

\begin{tabular}{lrrrrr}
\hline \multirow{2}{*}{ Station } & Observed peak & \multicolumn{2}{c}{ Simulated max surge $(\mathrm{cm})$} & \multicolumn{2}{c}{ Max surge difference (error, cm) } \\
\cline { 3 - 6 } & & Case 1 & Case 2 & Case 1 & Case 2 \\
\hline Goheung & 63.9 & 47.3 & 51.2 & $-16.6(-26.0 \%)$ & $-12.7(-19.9 \%)$ \\
Yeosu & 73.7 & 81.3 & 76.9 & $7.6(10.3 \%)$ & $3.2(4.3 \%)$ \\
Gwangyang & 100.5 & 61.1 & 72.5 & $-39.4(-39.2 \%)$ & $-28.0(-27.9 \%)$ \\
Tongyeong & 87.7 & 89.8 & 83.5 & $2.1(2.4 \%)$ & $-4.2(-4.8 \%)$ \\
Geoje & 66.7 & 56.0 & 55.0 & $-10.7(-16.0 \%)$ & $-11.7(-17.5 \%)$ \\
Masan & 106.1 & 143.0 & 117.4 & $36.9(34.8 \%)$ & $11.3(10.7 \%)$ \\
Gadeok & 65.0 & 62.3 & 59.5 & $-2.7(-4.2 \%)$ & $-5.5(-8.5 \%)$ \\
Busan & 59.7 & 62.7 & 61.1 & $3.0(5.0 \%)$ & $1.4(2.3 \%)$ \\
\hline RMSE & & & & $20.6 \mathrm{~cm}$ & $12.6 \mathrm{~cm}$ \\
\hline NRMSE & \multicolumn{4}{c}{$25.8 \%$} & $15.8 \%$ \\
\hline
\end{tabular}

Table 5. Simulated and observed maximum $H_{\mathrm{S}}$ for each scenario (see Figs. 4 and 9, and Table 1 for locations).

\begin{tabular}{lrrrrr}
\hline \multirow{2}{*}{$\begin{array}{l}\text { Station } \\
\text { name }\end{array}$} & $\begin{array}{r}\text { Observed } \\
\text { peak } H_{\mathrm{S}} \\
(\mathrm{m})\end{array}$ & $\begin{array}{c}\text { Simulated } \\
\text { maximum } H_{\mathrm{S}}\end{array}$ & \multicolumn{2}{c}{$\begin{array}{c}\text { Maximum } \\
\text { HS difference } \\
(\mathrm{m})\end{array}$} & \multicolumn{2}{c}{ Case 3} & Case 4 \\
\cline { 3 - 7 } & & Case 3 & Case 4 & & \\
\hline Yeosu buoy & 10.68 & 10.08 & 9.94 & $-0.60(-5.6 \%)$ & $-0.74(-6.9 \%)$ \\
Ganyeoam & 10.00 & 10.63 & 10.58 & $0.63(6.3 \%)$ & $0.58(5.8 \%)$ \\
KOGA-S03 & 10.76 & 11.88 & 11.88 & $1.12(10.4 \%)$ & $1.12(10.4 \%)$ \\
Dumido & 4.60 & 5.54 & 5.14 & $0.94(20.4 \%)$ & $0.54(11.7 \%)$ \\
Geoje buoy & 9.60 & 10.17 & 10.15 & $0.57(5.9 \%)$ & $0.55(5.7 \%)$ \\
Busan new port & 2.08 & 2.91 & 2.83 & $0.83(39.9 \%)$ & $0.75(36.1 \%)$ \\
Gwangan & 4.80 & 5.71 & 5.73 & $0.91(19.0 \%)$ & $0.93(19.4 \%)$ \\
Haeundae & 5.89 & 5.94 & 5.95 & $0.05(0.8 \%)$ & $0.06(1.0 \%)$ \\
KOGA-S02 & 7.95 & 9.31 & 9.28 & $1.36(17.1 \%)$ & $1.33(16.7 \%)$ \\
\hline & RMSE & & & $0.86 \mathrm{~m}$ & $0.81 \mathrm{~m}$ \\
\hline
\end{tabular}

agreement as in Eqs. (5) and (6),

$d=1-\frac{\sum_{n=1}^{N}\left(y_{n}-x_{n}\right)^{2}}{\sum_{n=1}^{N}\left(\left|y_{n}-\bar{y}\right|+\left|x_{n}-\bar{x}\right|\right)^{2}}$,

$\mathrm{RMSE}=\sqrt{\frac{\sum_{n=1}^{N}\left(y_{n}-x_{n}\right)^{2}}{N}}$,

where $N$ is the number of hourly computed and observed data at each station; $y_{n}$ and $x_{n}$ are respectively the simulated and measured wind speed and air pressure; $\bar{y}$ and $\bar{x}$ are the mean values of $y_{n}$ and $x_{n}$. This indicates perfect agreement in the cases of index $d=1$, while the index $d=0$ is in complete disagreement. Table 3 lists the values of the index $d$ and
RMSE for the wind speed and air pressure of each station. In the case of considering the wind dissipation effect by land roughness, the index $d$ and RMSE of the wind speed have clearly improved for all stations. The values of the index $d$ at eight stations are from 0.678 to 0.975 , whereas those values are from 0.885 to 0.993 when including land dissipation on the wind. The RMSE for the wind speed are also reduced from $5.43-10.55$ to $1.96-5.72 \mathrm{~m} \mathrm{~s}^{-1}$ under the same conditions. In terms of the mean values of indices, the mean index $d$ is modified from 0.917 to 0.972 , and the mean RMSE is modified from 7.84 to $4.03 \mathrm{~m} \mathrm{~s}^{-1}$. We can get higher values of index $d$ and lower values of RMSE at each measurement station by considering the effects of wind dissipation. This means that the simulation results of storm winds have better model/data agreement. Revised wind simulations permit us to apply storm surge and wave models to major storm events. 

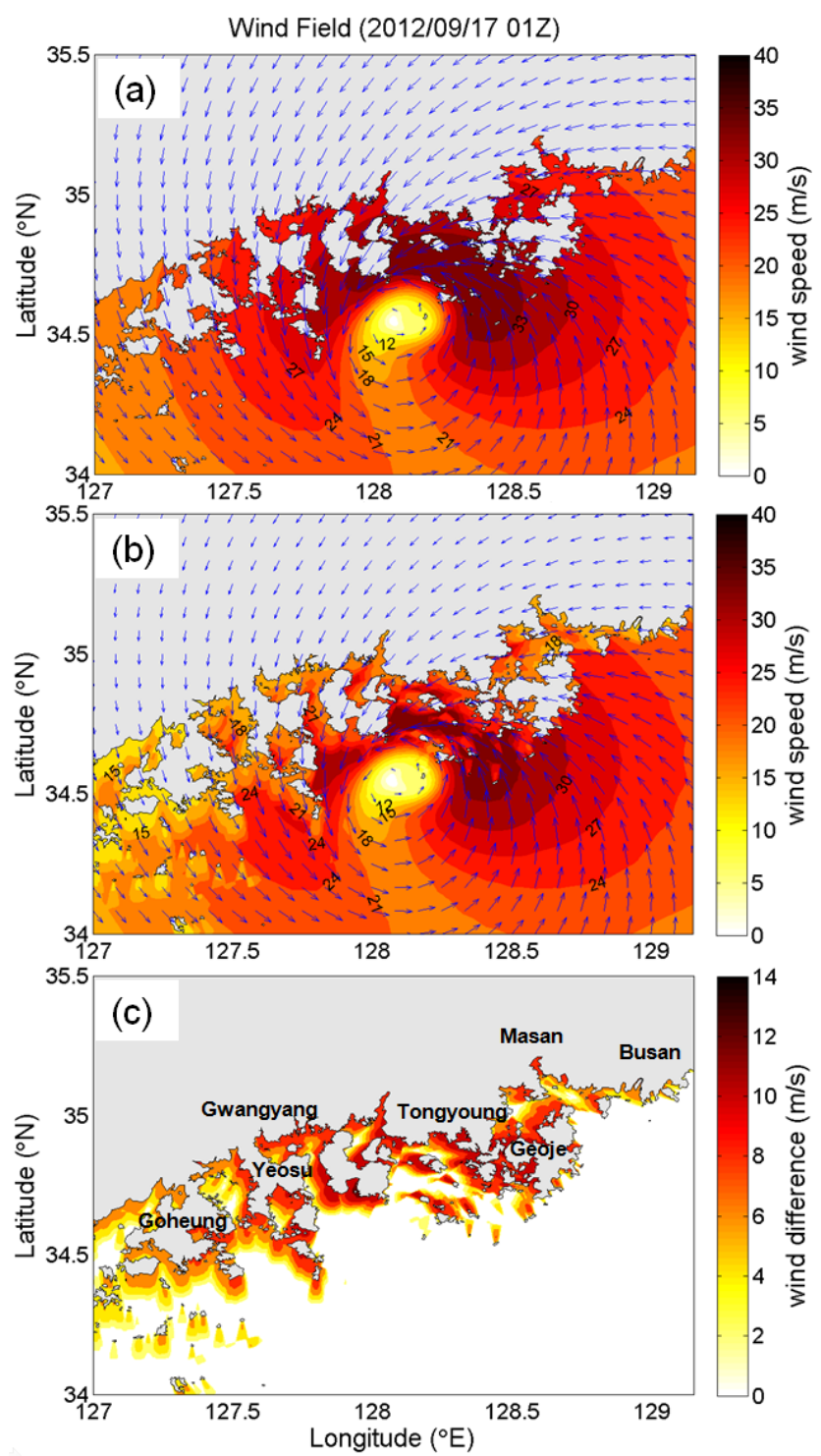

Figure 7. A comparison of simulated wind fields given the wind dissipation effect ((a) excluding land dissipation; (b) including land dissipation; (c) the magnitude of the dissipated wind speed).

\section{Simulation of storm surge and surface wave}

Storm surge is a phenomenon in which the ocean water surface elevation rises because of strong winds and atmospheric pressure decreases during typhoons and extratropical cyclones. The size and impact of storm surges are not relatively powerful in the deep sea. However, it could be significantly magnified in coastal areas in conjunction with geological effects, tides, tidal currents, and wave set-up/set-down by shallow-water waves. Severe storm surges occur more often in areas of relatively low depth. Aside from the effects of bottom friction, several other factors such as wind waves, swell effects, abnormal meteorological conditions, and resonance combined with long waves comprehensively influence the storm surge phenomenon. Therefore, the numerical models used to forecast storm surges should be developed to incorporate global characteristics, combining meteorological conditions like storms in the open sea and local geological features like the shape of the coastline and the width and slope of the ocean bottom in coastal areas. In this study, FVCOM, which is a high-resolution unstructured coastal grid model, is applied to a simulation of storm surges and surface waves, since this model can reflect complex irregular geometry in coastal ocean regions.

\subsection{Storm surges and surface wave models}

FVCOM employs the finite-volume method (FVM). FV$\mathrm{COM}$ combines the numerical flow of the finite-difference method (FDM) and the unstructured triangular grid system of the finite-element method (FEM). It contains the advantages of both methods. Specifically, it has discrete efficiency from FDM, and geometric flexibility that adopts geological complexity from FEM (C. Chen et al., 2007). Hence, this model has strength in reproducing complex coastlines and geological structure according to ocean depth. Additionally, it can achieve high efficiency in the computation of numerical models. Furthermore, this model supports parallel processing in computation. It is a 3-D model, which provides an obvious advantage over ADCIRC, which is 2-D model. Recently, an unstructured-grid and finite-volume version of the surface wave model SWAN has been developed, which is called FVCOM-SWAVE (Qi et al., 2009) and is linked with FVCOM. Moreover, its capability has been extended to enable coupled simulation combined with the effect of wavecurrent-sediment interaction (Wu et al., 2011).

The FVCOM model employs modified Mellor and Yamada (1982) level 2.5 and Smagorinsky (1963) turbulent closure schemes for vertical and horizontal mixing. FVCOM is implemented as either a mode-spilt solver or a semi-implicit solver. A wetting/drying treatment method was also adopted for inundation simulations. The original surface and the bottom stresses are derived by the drag equation, which is proportional to the quadratic velocity. The wind drag coefficient, $C_{\mathrm{D}}^{\mathrm{S}}$, was calculated with a modified version of the Large and Pond (1981) formula:

$$
C_{\mathrm{D}}^{\mathrm{S}}=\left\{\begin{array}{c}
0.0012 \text { if }\left|U_{10}\right| \leq 11 \mathrm{~m} \mathrm{~s}^{-1} \\
10^{-3}\left(0.49+0.065\left|U_{10}\right|\right) \text { if }\left|U_{10}\right| \geq 11 \mathrm{~m} \mathrm{~s}^{-1} \\
10^{-3}(0.49+0.065 \times 25) \text { if }\left|U_{10}\right| \geq 25 \mathrm{~m} \mathrm{~s}^{-1}
\end{array},\right.
$$

where $U_{10}$ is the wind velocity calculated by the TC 96 typhoon wind model at a height of $10 \mathrm{~m}$ above the sea surface. The bottom drag coefficient, $C_{\mathrm{D}}^{\mathrm{B}}$, was determined by matching a logarithmic bottom layer to the model at a height of $z$ above the bottom.

$$
C_{\mathrm{D}}^{\mathrm{B}}=\max \left(\frac{k^{2}}{\ln \left(z / z_{0^{\mathrm{B}}}\right)^{2}}, 0.0025\right)
$$

where $k$ is 0.4 , the von Karman constant, and $z_{0 \mathrm{~B}}$ is the bottom roughness parameter, which is essentially $0.001 \mathrm{~m}$ in the 


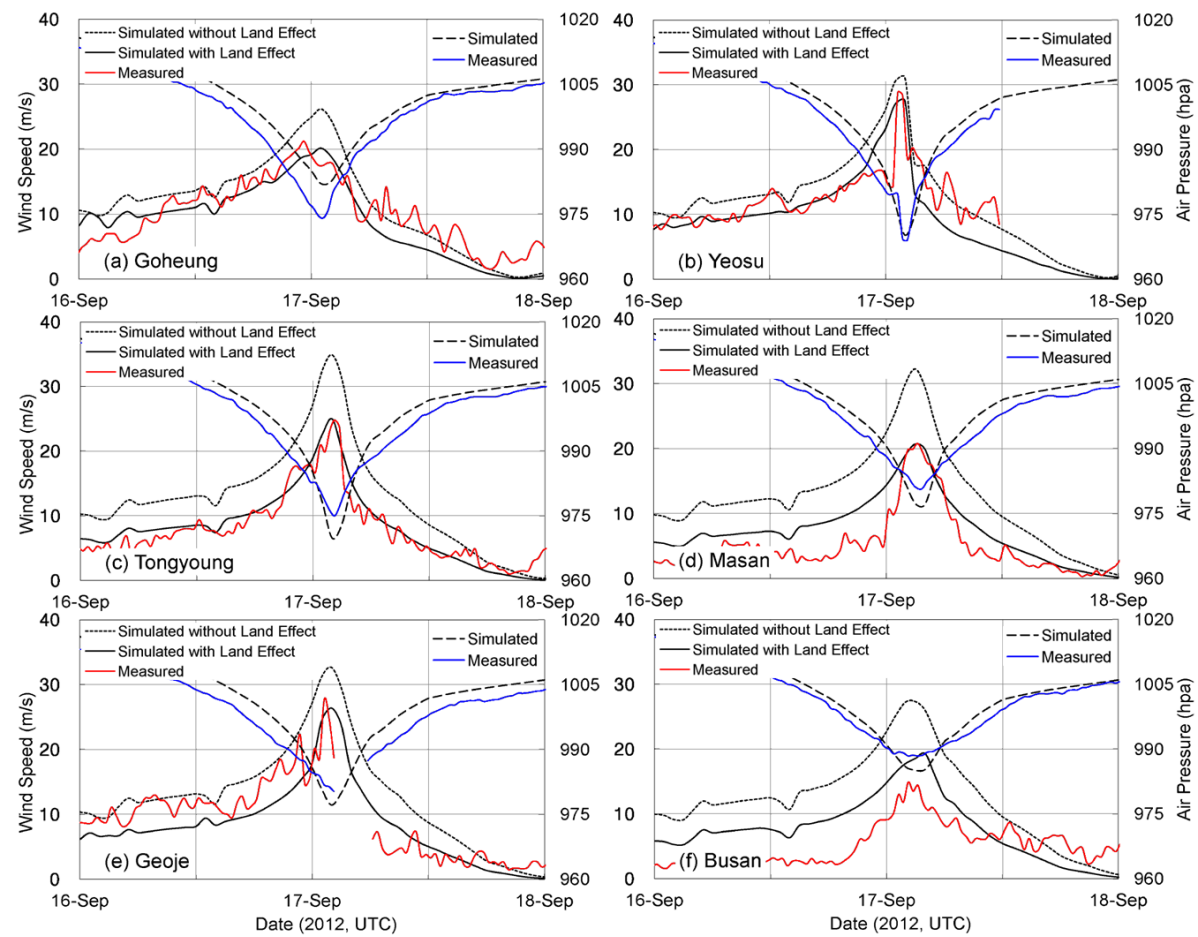

Figure 8. Comparison of wind speed (left) and air pressure (right) between the measured and simulated results during typhoon Sanba ((a) Goheung; (b) Yeosu; (c) Tongyoung; (d) Masan; (e) Geoje; (f) Busan).

ocean, but $0.1 \mathrm{~m}$ in low-lying land. However, in the coupled simulation with the wave model, these drag coefficients are related to the wave parameters.

The surface wave model FVCOM-SWAVE has the governing equation for the wave action density spectrum $N_{\mathrm{s}}$ written as follows:

$\frac{\partial N_{\mathrm{s}}}{\partial t}+\nabla \cdot\left[\left(C_{\mathrm{g}}+V\right) N_{\mathrm{s}}\right]+\frac{\partial C_{\sigma} N_{\mathrm{s}}}{\partial \sigma}+\frac{\partial C_{\theta} N_{\mathrm{s}}}{\partial \theta}=\frac{S_{\mathrm{tot}}}{\sigma}$,

where $C_{\sigma}$ and $C_{\theta}$ are the wave propagation velocities; $(\sigma, \theta)$ is the relative frequency and wave direction in spectral space. $S_{\text {tot }}$ is the source-sink term that incorporates the effects of wind-induced wave growth, wave breaking, bottom dissipation, and nonlinear wave-wave interactions (Qi et al., 2009). Detailed descriptions of the discrete methods in FVCOMSWAVE are provided in the SWAN technical manual (SWAN Team, 2006) and the Qi et al. (2009) study. Coupling between wave and current in FVCOM can be mainly approached through three procedures: the three-dimensional radiation stress, bottom boundary layer (BBL), and surface stress. Detailed algorithms for model coupling were described in Warner et al. (2008) and Wu et al. (2011).

In the present study, the numerical simulations of storm surges and surface waves are carried out using coupled FVCOM and FVCOM-SWAVE. Using this integrated model system, this study focuses on simulating and analyzing the effects of land dissipation on storm surges and surface waves. For these aims, we have simulated four scenarios:
- Case 1: Storm surge simulation using wind-forcing data, excluding the land dissipation effect;

- Case 2: Storm surge simulation using wind-forcing data, including the land dissipation effect;

- Case 3: Wave simulation using wind-forcing data, excluding the land dissipation effect;

- Case 4: Wave simulation using wind-forcing data, including the land dissipation effect.

The final simulation results for storm surges were obtained by subtracting the simulation results for only tides from the results for both tides and surges. For each case, the simulation results have been compared to observation records of storm surges and waves. Through these comparisons, we investigated the effects of land roughness on the model results. To interpret the skill assessment of model results, the following indices are adopted: RMSE and normalized root mean square error (NRMSE):

$\mathrm{RMSE}=\sqrt{\frac{\sum_{j=1}^{J}\left(y_{j}-x_{j}\right)^{2}}{J}}$, 


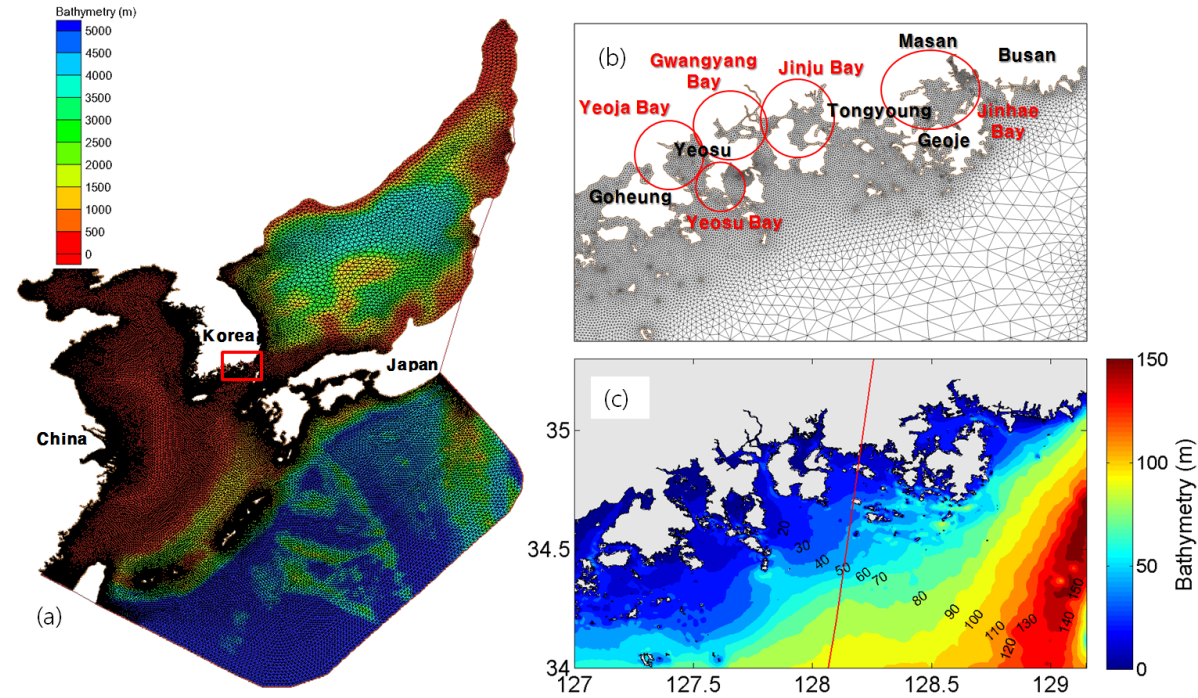

Figure 9. Overview of the model domain ((a) grid composition and bathymetry distribution; (b) enlarged grid view of the southern coast of Korea; (c) enlarged bathymetry view of the southern coast of Korea with a typhoon pass (red line)).

$\mathrm{NRMSE}=\sqrt{\frac{\sum_{j=1}^{J}\left(y_{j}-x_{j}\right)^{2}}{\sum_{j=1}^{J} y_{j}^{2}}}$,

where $J$ is the number of observed data stations, $y_{j}$ and $x_{j}$ are the simulated and measured peak storm surges or wave heights at each station. The indices presented as Eq. (10), Eq. (11) indicate the simulation errors only for the peak values at each measurement. The NRMSE is expressed as a percentage.

\subsection{Mesh generation and boundary conditions}

In this study, we defined a model domain that included the seas surrounding Korea and the East China Sea. A large unstructured grid of approximately $1-10 \mathrm{~km}$ size was applied to the open sea. Very small triangular meshes of less than $50 \mathrm{~m}$ were used locally to refine details in regions that were of interest. The domain covers an extensive range of 118 $142^{\circ} \mathrm{E}$ longitude and $19-52^{\circ} \mathrm{N}$ latitude (Fig. 9a). The triangular grid has 122983 nodes and 233152 elements. Figure $9 \mathrm{~b}$ shows an enlarged view with fine resolution near the coast along the southern area of Korea. Eleven $\sigma$ levels were used in the vertical, while the bathymetry data near the coast were obtained from digital nautical charts and field measurements (Seo, 2008), the bathymetry of other model areas was interpolated linearly from the ETOPO1 data set (Amante and Eakins, 2008; Fig. 9a, c). In simulating the tide, eight main component tide values (M2, S2, K1, O1, N2, P1, K2, Q1) were used as a harmonic constant applied to the open bound- ary by referring to the $1 / 12^{\circ}$ grid of NAO99jb (Matsumoto et al., 2000).

\subsection{Storm surge results}

The simulation results for surge height were compared to the observation data for each case. The observation data for surge height were obtained by removing the tide element from the predicted tide values, which were evaluated by analyzing past tide data recorded at tidal stations. The observation data were used to verify the simulation results. Figure 10 suggests that temporal variations at tidal stations were observed at significantly higher surge heights during Typhoon Sanba because it is located close to the track of the typhoon. Table 4 compares the maximum surge heights of the simulation and the observations for each scenario and station, respectively. Figure 10 presents the variations of surge height at the tidal stations by whether or not the land dissipation effect exists (Case 1 vs. Case 2). Figure 12 shows storm surge and wind field distributions at different times before and after typhoon landfall. As the typhoon landfall gets closer, the surge height rises become more obvious. In terms of the region, the simulation results indicate that the maximum surge heights are distributed up to $150 \mathrm{~cm}$ (Fig. 12a). As it gets closer to the time when landfall takes place, areas such as Goheung, Yeosu, Gwangyang, Masan, and Tongyoung show relatively higher wind dissipation effects due to the land effect by their geological characteristics. In those areas, there are evident differences in surge heights due to wind speed differences, as shown in Fig. 10. In particular, in the case of Masan (Fig. 10d), which is located inside a funnel-shaped bay, the difference is more obvious than for the others. When the wind dissipation by land roughness effect is not considered, the simulation results for the maximum surge height are 

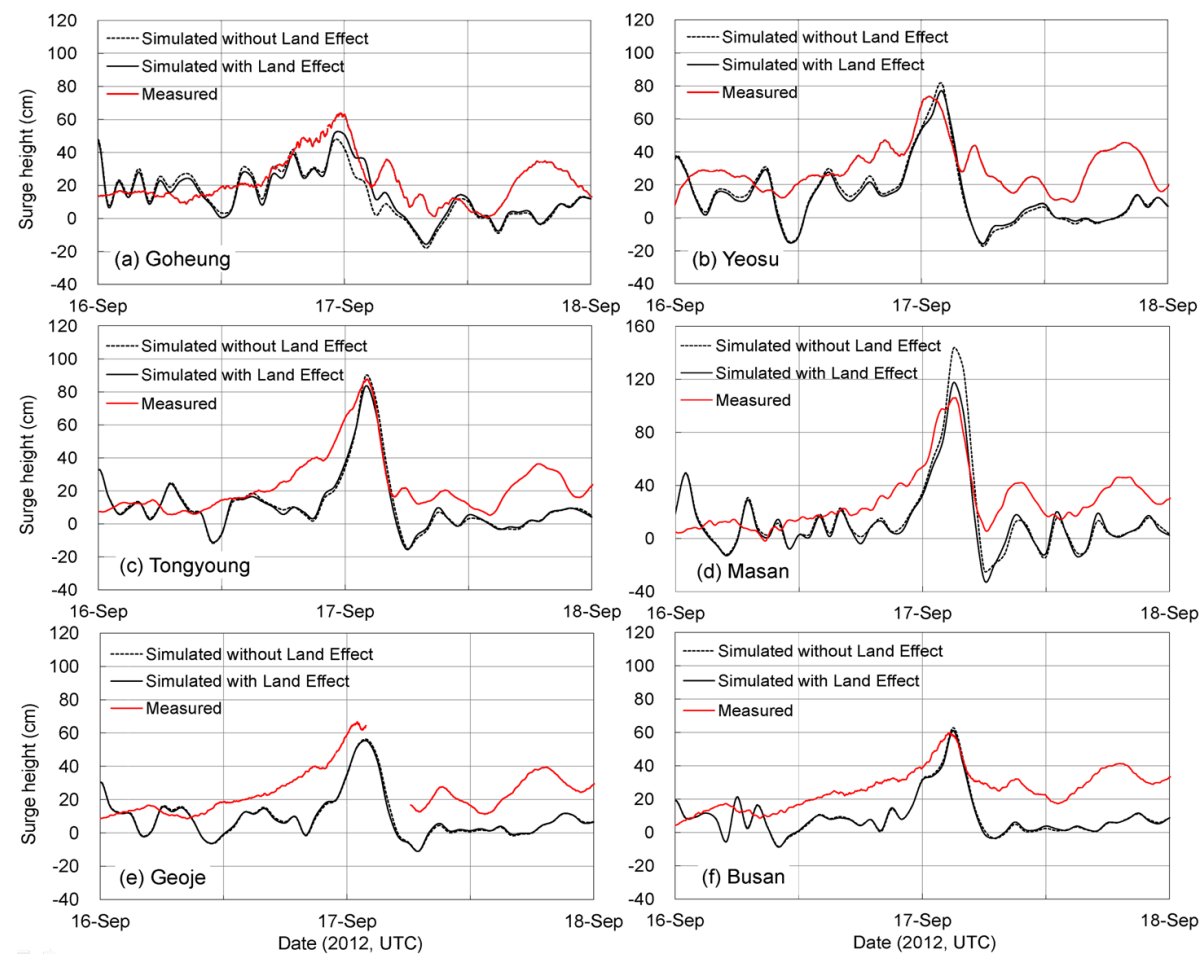

Figure 10. Comparison of the surge height on the influence of the land roughness effect during typhoon Sanba ((a) Goheung; (b) Yeosu; (c) Tongyoung; (d) Masan; (e) Geoje; (f) Busan).
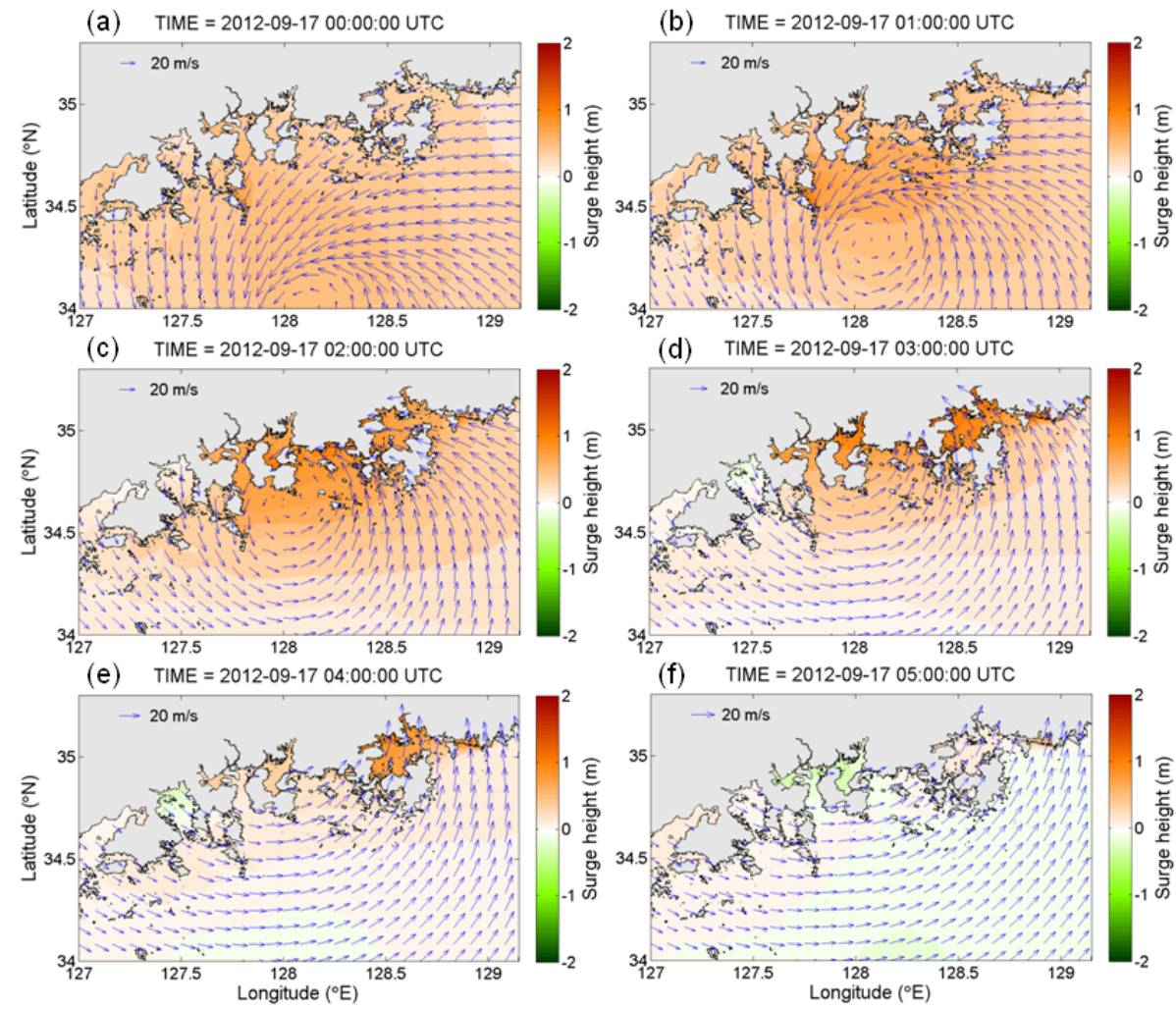

Figure 11. Storm surge and wind field distributions during typhoon landfall, contours denote the storm surge height and vectors denote the wind speed and direction. 

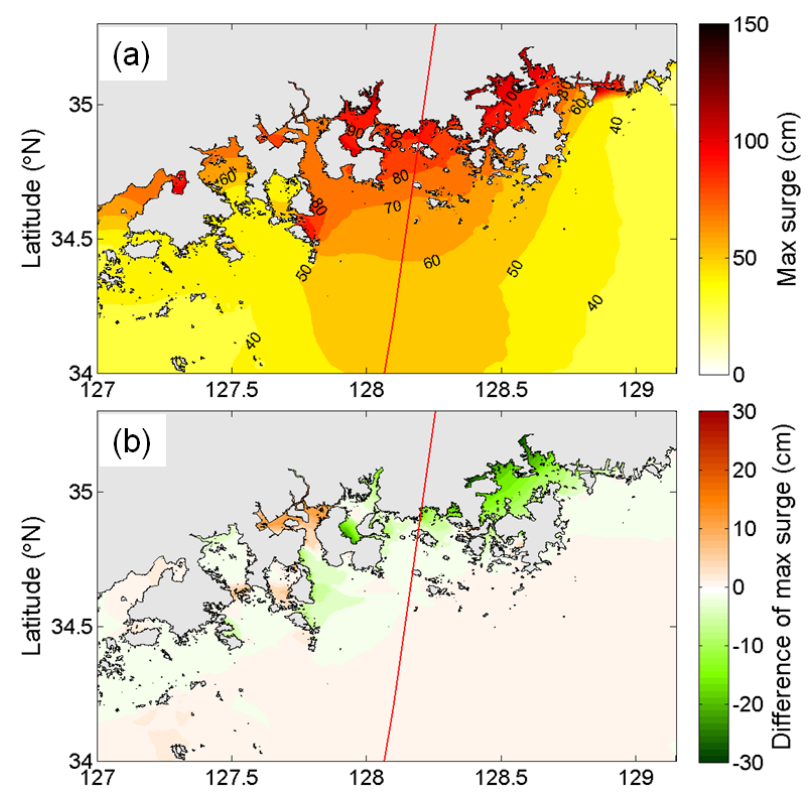

Figure 12. Spatial distribution of the storm surge during Typhoon Sanba ((a) Maximum cumulative storm surge height; (b) difference of maximum surge considering the land roughness effect).

relatively higher than the observed data, because of the application of overestimated surface shear stresses. In contrast, in consideration of the land roughness effect for the wind force, the error of the maximum surge height between the simulation and observation data gets sharply lower from $36.9 \mathrm{~cm}$ (34.8\%) to $11.3 \mathrm{~cm}(10.7 \%)$ (Fig. 10d, Table 4).

From the perspective of the typhoon's track, we can observe that the maximum surge heights in Masan, Tongyoung, and Gadeok, which are located to the right side of the center of the typhoon show to be lower in simulation results that include the wind dissipation effects. This is because these areas are influenced by weaker, onshore-directed (from ocean to land) winds. However, in the cases of the left side areas such as Gwangyang and Goheung, maximum surge heights were simulated as higher for the same conditions. These findings indicate that wind direction is an important factor that affects the spatial distribution of local surge heights. In the case of areas that are located to the left side of the typhoon, offshoredirected (from land to ocean) winds becomes weaker due to land roughness effect. Therefore, relatively lower oppositedirected wind-driven surges can occur from it, as shown in Fig. 11a. Figure 11 shows spatial distribution of storm surge and wind for the each time of typhoon passing.

According to Fig. 10a, in the case of Goheung, surge heights without the inclusion of a land effect were oversimulated compared to those that included the effect until the typhoon passed through the area. Once the typhoon had passed through, the surge height became lower. In contrast, Masan showed opposite phenomenon, since Masan is located to the right side of the typhoon (Fig. 10d). According to
Fig. 12b, during the travels of Typhoon Sanba, we examined the spatial distribution of the differences of the maximum surge heights that occurred by wind dissipation due to the land roughness effect. On the right side of the typhoon, the maximum surge height decreased due to the land roughness effect. On the left side of the typhoon, conversely, the maximum surge height increased. This effect is an important factor that influences storm surge simulation. As suggested by Table 4, this effect enhances the numerical simulation results in every nearby observation station. Interestingly, in some areas such as Geoje and Busan, the differences do not appear to a significant degree. This implies that the storm winds blowing in these areas are not much influenced by the land, because these areas face offshore.

Based on the storm surge simulation results for each scenario presented in Table 4, the improvement degrees of RMSE and NRMSE for storm surges at eight different observation positions can be summarized as follows:

Case 2 indicates that the error (error rate) decreases significantly compared to Case 1 . The RMSE and NRMSE for the peak surge heights are reduced from $20.6 \mathrm{~cm}$ and $25.8 \%$ to $12.6 \mathrm{~cm}$ and $15.8 \%$ after incorporating the wind dissipation effects. The land effect contributes improvements of an average error rate of peak surge height by up to $10.0 \%$. In particular, an improvement of up to $24.1 \%$ in the peak surge error is shown at the Masan station. Therefore, it is indicated that the wind dissipation effect by land roughness is a significant factor to the accurate simulation of storm surges.

\subsection{Surface wave results}

In terms of waves, observations have been performed during Typhoon Sanba at several locations. Using those data, we examined wave simulation results. Simulation scenarios for waves differ by whether or not the land dissipation effect exists (Case 3 vs. Case 4). The measured significant wave heights are presented with the numerical simulation results for each observation station in Fig. 13. As shown in Fig. 13, these simulation results well explain the observed peak of wave heights and phases. However, in entire areas except for Yeosu, the simulated values for peak wave heights are likely to be a little higher than the observed data. Additionally, wave height values before reaching peak values have a tendency of being slightly overestimated, and there is no significant difference in the maximum significant wave height according to the land dissipation effect, except for at Dumido station (Fig. 13b).

This is because the stations in which the waves were observed are likely to be located offshore in the deep sea, or in places without a land effect within the wave fetch length. According to Fig. 14b, the spatial distribution of the difference in the maximum significant wave height that occurs depending on the land dissipation effect can be well recognized. The simulation results indicate that the wave height drops lower due to the wind, which is weakened while passing through 


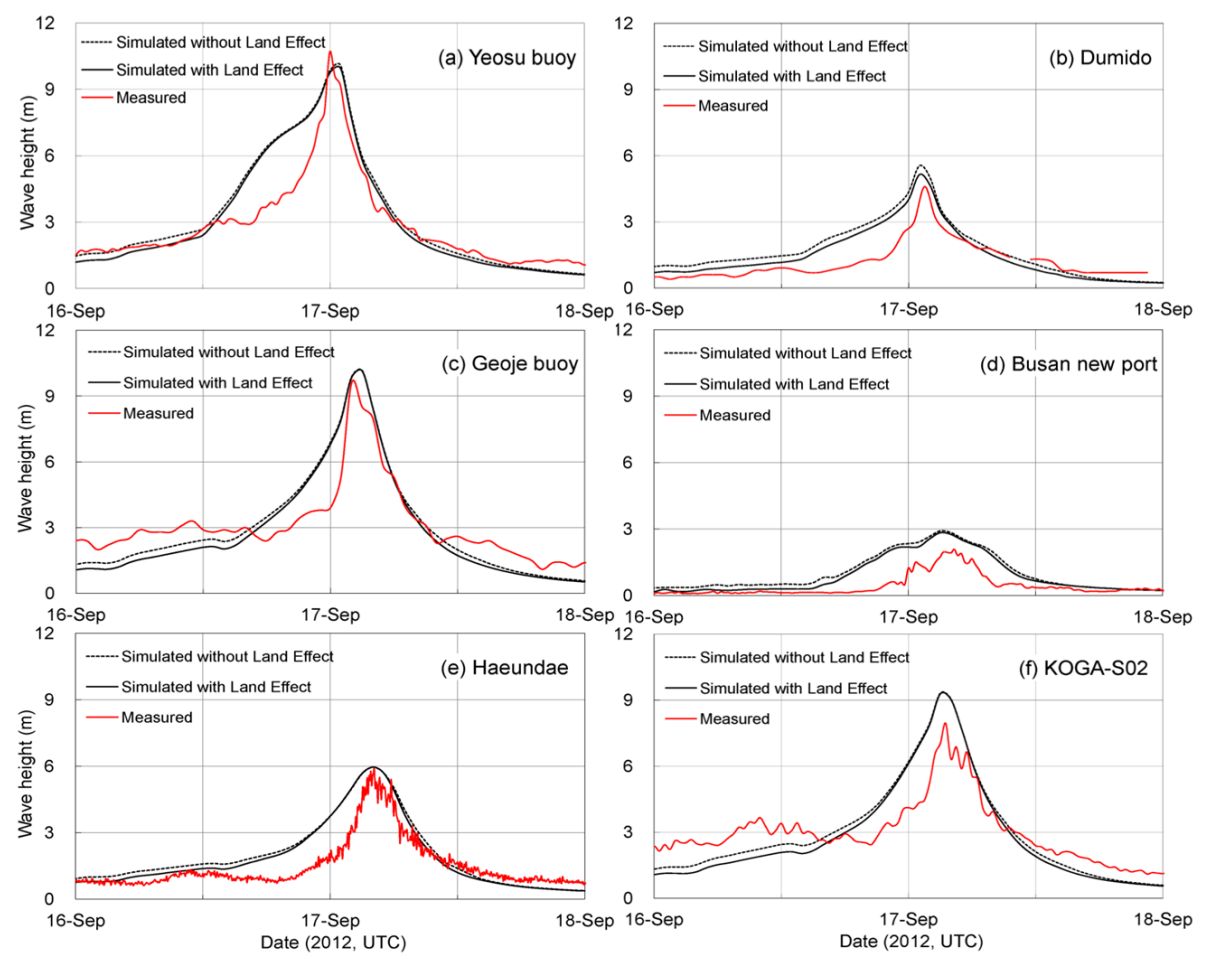

Figure 13. Simulated (Case 3 and Case 4) and observed wave heights during typhoon Sanba ((a) Yeosu buoy; (b) Dumido; (c) Geoje buoy; (d) Busan new port; (e) Haeundae; (f) KOGA-S02).

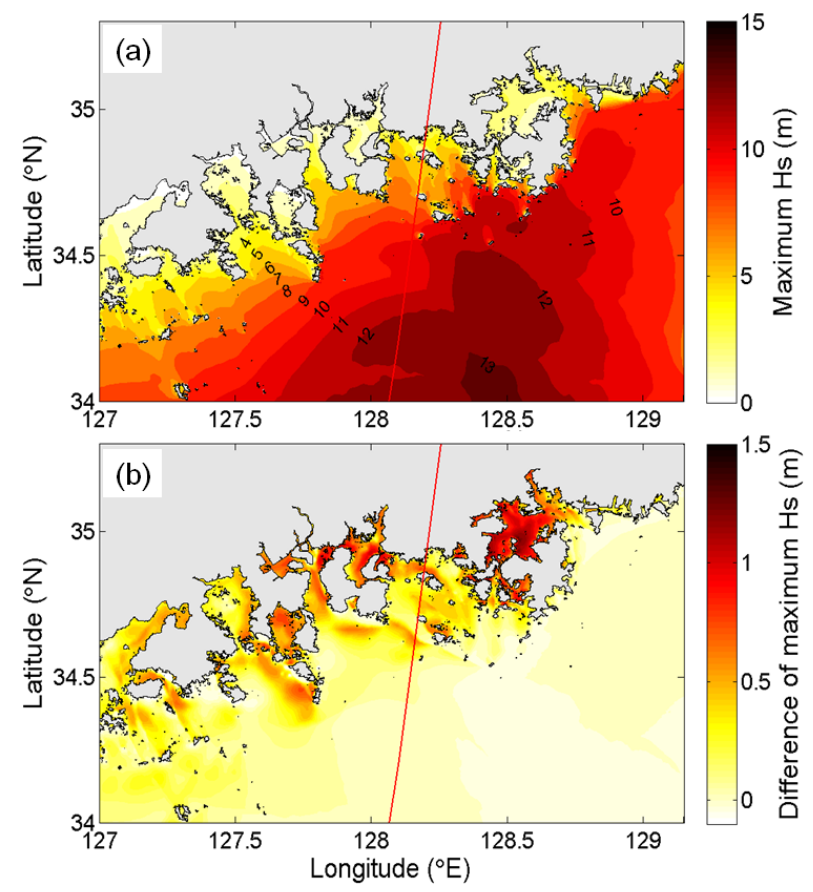

Figure 14. Spatial distribution of the wave heights during Typhoon Sanba ((a) Maximum $H_{\mathrm{S}}$; (b) Maximum $H_{\mathrm{S}}$ difference (decrement) according to the existence of the land roughness effect). the land. In the western region of Jinhae Bay, the wave height can be reduced by up to $1.2 \mathrm{~m}$. These tendencies are outstandingly obvious in areas that are less than $30 \mathrm{~m}$ deep, and in inner bays surrounded by land such as Jinju Bay, Gwangyang Bay, and Yeosu Bay.

Figure 14a presents the spatial distribution of the simulation results for the maximum significant wave heights during Typhoon Sanba. At the right side of the typhoon, around the area of the maximum wind speed, the significant wave heights are simulated as being higher than $13 \mathrm{~m}$. Due to geological characteristics such as complicated coastlines, lower wave heights are simulated in major inner bay areas. Table 5 presents simulation results for maximum significant waves and their difference errors, along with RMSE and NRMSE for the peak wave heights during Typhoon Sanba at nine observation stations that were adjacent to the track of the typhoon, holding available observation data. In the scenario of considering land dissipation effects, the RMSE and NRMSE of the maximum significant wave height were slightly lowered, from $0.86 \mathrm{~m}$ and $10.8 \%$ to $0.81 \mathrm{~m}$ and $10.2 \%$, respectively, compared with the scenario that does not consider any land dissipation effect. According to the presently available observation data, improvement effects appear in a restricted way. However, as suggested in Fig. 14b, wave height reductions of up to $1.2 \mathrm{~m}$ were distributed partially when peak wave heights occurred. If we could acquire observational data for wave heights at locations where the simulated val- 
ues indicate that the land dissipation effect appears relatively higher, we expect to be able to analyze more quantitative improvement in its effects.

\section{Conclusions}

In the present study, we performed numerical simulations for storm winds, surges, and surface waves caused by Typhoon Sanba in 2012, using an integrated model system. Simulation has been done for the areas that were significantly damaged by flooding and inundation due to the severity of the storm surge and waves during Typhoon Sanba.

It is found that the temporal and spatial distributions of simulated results seem to be well reproduced compared to the observational data. In particular, we could obtain better simulation results compared to the observation data when we consider the wind dissipation effects by land roughness with various land use types for wind field generation. Without considering land roughness, it is verified that the wind speed passing through the land is often overestimated. In terms of the simulation of storm surges, peak surge heights according to typhoon landfall tend to be underestimated at the left side of the typhoon. At the right side, conversely, they tend to be overestimated. However, we were able to get better results when we considered the effects of wind dissipation. The simulation results indicated that these tendencies are significantly improved when a wind dissipation effect is included in the simulations.

The storm surge results indicated that the maximum surge heights reached up to $150 \mathrm{~cm}$ inside the bay. Looking at the improvement of the simulation results for each scenario, we find that the RMSE and NRMSE of the maximum surge heights are respectively $20.6 \mathrm{~cm}$ and $25.8 \%$, when not considering wind dissipation. However, it is shown that RMSE and NRMSE substantially decrease by up to $12.6 \mathrm{~cm}$ and $15.8 \%$ when including the effects of wind dissipation. In terms of wave simulation results, the maximum significant wave height reaches up to $13 \mathrm{~m}$ offshore, while the wave height appears to be approximately $2-3 \mathrm{~m}$ high in southern coastal areas, for geological reasons. It is also found that wind dissipation effects influence the generation of waves. In an inner bay area, which is more greatly influenced by the land, the wave reduction effect appears relatively high. Hence, this implies that the wind dissipation effect due to land roughness should be taken into account when simulating storm surges and surface waves.

In this study, storm surges and surface waves are simulated more accurately by considering the effects of wind dissipation. This demonstrates the effectiveness of improving our approach to surge and wave predictions for coastal regions. It is expected that the present study could contribute to improving the accuracy of coastal inundation prediction systems for storm-induced surges and waves to some extent. The model system used in this study could be applied to sub- sequent studies on typhoons making landfall on other coasts such as the western and southwestern coasts of Korea. Moreover, investigation of structured morphology effects on land roughness considering topography features such as land elevation and building heights is still needed. This could also be one of the important factors of the land roughness, and the study of this will form part of our future work. Furthermore, a detailed analysis of the coupling effect of the wave-current interaction procedure would be a logical follow-up to this study.

Acknowledgements. We would like to thank our editor and anonymous reviewers for their helpful and constructive comments. This work was supported by the projects, "Estimation of storm surge inundation and hazard mapping" and "Analysis and prediction of disastrous coastal waves", which were funded by the Korea Institute of Ocean Science \& Technology. This research was also a part of a project entitled "Development of Korea Operational Oceanographic System (KOOS) Phase 2" and "Construction of Ocean Research Station and their Application Studies" which were funded by the Ministry of Oceans and Fisheries, South Korea.

Edited by: G. Panegrossi

Reviewed by: two anonymous referees

\section{References}

Amante, C. and Eakins, B. W.: Etopo1 1 Arc-Minute Global Relief Model: Procedures, Data Sources and Analysis, Technical report, National Geophysical Data Center, NESDIS, NOAA, US Department of Commerce, Boulder, Colorado, USA, 2008.

Anthes, R. A.: Tropical cyclones: their evolution, structure, and effects, Meteor. Mon., 41, p. 208, 1982.

Bender, M. A., Ginis, I., Tuleya, R., Thomas, B., and Marchok, T.: The operational GFDL coupled hurricane-ocean prediction system and a summary of its performance, Mon. Weather Rev., 135, 3965-3989, 2007.

Bunya, S., Dietrich, J. C., Westerink, J. J., Ebersole, B. A., Smith, J. M., Atkinson, J. H., Jensen, R., Resio, D. T., Luettich, R. A., Dawson, C., Cardone, V. J., Cox, A. T., Powell, M. D., Westerink, H. J., and Roberts, H. J.: A high-resolution coupled riverline flow, tide, wind, wind wave, and storm surge model for southern Louisiana and Mississippi. Part I: Model development and validation, Mon. Weather Rev., 138, 345-377, 2010.

Cardone, V. J., Cox, A. T., Greenwood, J. A., and Thompson, E. F.: Upgrade of the tropical cyclone surface wind field model, Miscellaneous Paper CERC-94-14, US Army Corps of Engineers, 101, 1994, available from ERDC Vicksburg (WES), US Army Engineer Waterways Experiment Station (WES), ATTN: ERDCITL-K, 3909 Halls Ferry Rd., Vicksburg, MS 39180-6199, 1994.

Chen, C., Cowles, G., and Beardsley, R. C.: An unstructured grid, finite-volume coastal ocean model: FVCOM user manual, UMASS-Dartmouth Technical Report-04-0601, University of Massachusetts, School of marine Science and Technology, New Bedford, Massachusetts, USA, 2004. 
Chen, C., Beardsley, R. C., and Cowles, G.: An unstructured grid, finite-volume coastal ocean model (FVCOM) system, Oceanography, 19, 78-89, 2006.

Chen, C., Huang, H., Beardsley, R. C., Liu, H., Xu, Q., and Cowles, G.: A finite volume numerical approach for coastal ocean circulation studies: comparisons with finite difference models, J. Geophys. Res.-Oceans, 112, C03018, doi:10.1029/2006JC003485, 2007.

Chen, S. S., Zhao, W., Donelan, M. A., Price, J. F., and Walsh, E. J.: The CBLAST-Hurricane program and the next-generation fully coupled atmosphere-wave-ocean models for hurricane research and prediction, B. Am. Meteorol. Soc., 88, 311-317, 2007.

Corbosiero, K. L., Wang, W., Chen, Y., Dudhia, J., and Davis, C.: Advanced research WRF high frequency model simulations of the inner core structure of Hurricanes Katrina and Rita (2005), in: Proceedings of the 8th WRF User's Workshop, National Center for Atmospheric Research, 11-15 June 2007, Boulder, CO, USA, 2007.

Cox, A. T., Greenwood, J. A., Cardone, V. J., and Swail, V. R.: An interactive objective kinematic analysis system, in: Proceedings of the 4th International Workshop on Wave Hindcasting and Forecasting, 109-118, 16-20 October 1995, Ban?, Alberta, Canada, 1995.

Dietrich, J. C., Westerink, J. J., Kennedy, A. B., Smith, J. M., Jensen, R. E., Zijlema, M., Holthuijsen, L. H., Dawson, R. A., Luettich Jr., R. A., Powell, M. D., Cardone, V. J., Cox, A. T., Stone, G. W., Pourtaheri, H., Hope, M. E., Tanaka, S., Westerink, L. G., Westerink, H. J., and Cobell, Z.: Hurricane Gustav (2008) waves and storm surge: hindcast, synoptic analysis, and validation in Southern Louisiana, Mon. Weather Rev., 139, 2488-2522, 2011a.

Dietrich, J. C., Zijlema, M., Westerink, J. J., Holthuijsen, L. H., Dawson, C., Luettich Jr., R. A., Jensen, R. E., Smith, J. M., Stelling, G. S., and Stone, G. W.: Modeling hurricane waves and storm surge using integrally-coupled, scalable computations, Coast. Eng., 58, 45-65, 2011 b.

Graber, H. C., Cardone, V. J., Jensen, R. E., Slinn, D. N., Hagen, S. C., Cox, A. T., Powell, M. D., and Grassl, C.: Coastal forecasts and storm surge predictions for tropical cyclones: a timely partnership program, Oceanography, 19, 130-141, 2006.

Hartley, S., Pace III, R., Johnston, J. B., Swann, M., O’Neil, C., Handley, L., and Smith, L.: A GAP Analysis of Louisiana: Final Report and Data: Lafayette, Louisiana, US Department of the Interior, US Geological Survey, Washington DC, 2000.

Holland, G. J.: An analytic model of the wind and pressure profiles in hurricanes, Mon. Weather Rev., 108, 1212-1218, 1980.

Hsu, S. A. and Babin, A.: Estimating the radius of maximum wind via satellite during Hurricane Lili (2002) over the Gulf of Mexico, Nat. Weather Assoc. Electronic J., 2005-EJ3, available at: http://www.nwas.org/ej/hsu/hsu_babin_2005.pdf, 2005.

Hsu, S. A., Meindl, E. A., and Gilhousen, D. B.: Determining the power-law wind-profile exponent under near-neutral stability conditions at sea, J. Appl. Meteorol., 33, 757-765, 1994.

Hsu, S. A., Martin Jr., M. F., and Blanchard, B. W.: An evaluation of the USACE's deepwater wave prediction techniques under hurricane conditions during Georges in 1998, J. Coastal Res., 16, 823-829, 2000.
Kang, S. W., Jun, K. C., Park, K. S., and Han, S. D.: Storm surge hindcasting of typhoon Maemi in Masan Bay, Korea, J. Mar. Geod., 32, 1-14, 2009.

Kawai, H., Kim, D. S., Kang, Y. K., Tomita, T., and Hiraishi, T.: Hindcasting of storm surge at southeast coast by Typhoon Maemi, J. Korean Soc. Ocean Eng., 19, 12-18, 2005.

Kieu, C. Q.: An investigation into the contraction of the hurricane radius of maximum wind, Meteorol. Atmos. Phys., 115, 47-56, 2012.

Kwon, J. I., Lee, J. C., Park, K. S., and Jun, K. C.: Comparison of typhoon wind models based on storm surge heights induced by typhoon Maemi, Asia-Pac. J. Atmos. Sci., 44, 443-454, 2008.

Lam, J. S. L., Lau, A. K. H., and Fung, J. C. H.: Application of re?ned land-use categories for high resolution mesoscale atmospheric modelling, Bound.-Lay. Meteorol., 119, 263-288, 2006.

Large, W. G. and Pond, S.: Open ocean momentum flux measurements in moderate to strong winds, J. Phys. Oceanogr., 11, 324 336,1981 .

Lee, J. C., Kwon, J. I., Park, K. S., and Jun, K. C.: Calculations of storm surges, typhoon Maemi, J. Korean Soc. Coastal Ocean Eng., 20, 93-100, 2008.

Loveland, T. R., Reed, B. C., Brown, J. F., Ohlen, D. O., Zhu, Z., Yang, L. W. M. J., and Merchant, J. W.: Development of a global land cover characteristics database and IGBP DISCover from 1 km AVHRR data, Int. J. Remote Sens., 21, 1303-1330, 2000.

Luettich Jr., R. A., Westerink, J. J., and Scheffner, N. W.: ADCIRC: an Advanced Three-Dimensional Circulation Model for Shelves, Coasts and Estuaries. Report 1: Theory and Methodology of ADCIRC-2DDI and ADCIRC-3DL, US Army Corps of Engineers, Technical Report DRP-92-6, Coastal Engineering Research Center, Vicksburg, Mississippi, USA, 1992.

Matsumoto, K., Takanezawa, T., and Ooe, M.: Ocean tide models developed by assimilating TOPEX/POSEIDON altimeter data into hydrodynamical model: a global model and a regional model around Japan, J. Oceanogr., 56, 567-581, 2000.

Mellor, G. L. and Yamada, T.: Development of a turbulence closure model for geophysical fluid problems, Rev. Geophys., 20, 851875, 1982.

Powell, M. D., Houston, S. H., and Reinhold, T. A.: Hurricane Andrew's landfall in south Florida. Part I: Standardizing measurements for documentation of surface wind fields, Weather Forecast., 11, 304-328, 1996.

Powell, M. D., Houston, S. H., Amat, L. R., and Morisseau-Leroy, N.: The HRD real-time hurricane wind analysis system, J. Wind Eng. Ind. Aerod., 77, 53-64, 1998.

Powell, M. D., Murillo, S., Dodge, P., Uhlhorn, E., Gamache, J., Cardone, V., Cox, A., Otero, S., Carrasco, N., Annane, B., and St. Fleur, R.: Reconstruction of Hurricane Katrina's wind fields for storm surge and wave hindcasting, Ocean Eng., 37, 26-36, 2010.

Qi, J., Chen, C., Beardsley, R. C., Perrie, W., Cowles, G. W., and Lai, Z: : An unstructured grid finite-volume surface wave model (FVCOM-SWAVE): implementation, validations and applications, Ocean Model., 28, 153-166, 2009.

Seo, S. N.: Digital $30 \mathrm{sec}$ gridded bathymetric data of Korea marginal seas - KorBathy30s, J. Korean Soc. Coastal Ocean Eng., 20, 110-120, 2008 (in Korean).

Sheng, Y. P., Zhang, Y., and Paramygin, V. A.: Simulation of storm surge, wave, and coastal inundation in the Northeastern Gulf of 
Mexico region during Hurricane Ivan in 2004, Ocean Model., 35, 314-331, 2010.

Skamarock, W. C., Klemp, J. B., Dudhia, J., Gill, D. O., Barker, D. M., Wang, W., and Powers, J. G.: A Description of the Advanced Research WRF Version 2, NCAR Tech. Note NCAR/TN468STR, Mesoscale and Microscale Meteorology Div., National Center for Atmospheric Research, Boulder, CO, 2005.

Smagorinsky, J.: General circulation experiments with the primitive equations. Part I. The basic experiment, Mon. Weather Rev., 91, 99-164, 1963.

SWAN Team: SWAN Cycle III Version 40.51 User Manual, Delft University of Technology, Faculty of Civil Engineering and Geosciences, Environmental Fluid Mechanics Section, Delft, Netherlands, 2006.

Thompson, E. F. and Cardone, V. J.: Practical modeling of hurricane surface wind field, J. Waterw. Port C.-ASCE, 122, 195-205, 1996.

Warner, J. C., Sherwood, C. R., Signell, R. P., Harris, C. K., and Arango, H. G.: Development of a three-dimensional, regional, coupled wave, current, and sediment-transport model, Comput. Geosci., 34, 1284-1306, 2008.
Westerink, J. J., Luettich Jr., R. A., Blain, C. A., and Scheffner, N. W.: ADCIRC: an Advanced Three-Dimensional Circulation Model for Shelves, Coasts, and Estuaries, Report 2. User's Manual for ADCIRC-2DDI, Technical Report DRP-94, US Army Corps of Engineers, Washington DC, 1994.

Westerink, J. J., Luettich, R. A., Feyen, J. C., Atkinson, J. H., Dawson, C., Roberts, H. J., Powell, M. D., Dunion, J. P., Kubatko, E. J., and Pourtaheri, H.: A basin-to channel-scale unstructured grid hurricane storm surge model applied to southern Louisiana, Mon. Weather Rev., 136, 833-864, 2008.

Willmott, C. J.: On the validation of models, Phys. Geogr., 2, 184 194, 1981.

Wu, L., Chen, C., Guo, P., Shi, M., Qi, J., and Ge, J.: A FVCOMbased unstructured grid wave, current, sediment transport model, I. Model description and validation, J. Ocean University of China, 10, 1-8, 2011.

Xie, L., Bao, S., Pietrafesa, L. J., Foley, K., and Fuentes, M.: A realtime hurricane surface wind forecasting model: Formulation and verification, Mon. Weather Rev., 134, 1355-1370, 2006.

Yoon, J. J. and Shim, J. S.: Estimation of storm surge inundation and hazard mapping for the southern coast of Korea, in: Proceedings of the 12th International Coastal Symposium, J. Coastal Res., Special Issue, 65, 856-861, 8-12 April 2013, Plymouth, UK, 2013. 